\title{
Lysosomal perturbations in dopaminergic neurons derived from induced pluripotent stem cells with $P A R K 2$ mutation
}

Justyna Okarmus ${ }^{1 *}$, Helle Bogetofte ${ }^{1 *}$, Sissel Ida Schmidt ${ }^{1}$, Matias Ryding ${ }^{1}$, Silvia Garcia Lopez ${ }^{2}$, Alberto Martínez-Serrano ${ }^{2}$, Poul Hyttel ${ }^{3}$, Morten Meyer ${ }^{1,4}$

${ }^{1}$ Department of Neurobiology Research, Institute of Molecular Medicine, University of Southern Denmark, J.B. Winsløws Vej 21, 5000 Odense C, Denmark; ${ }^{2}$ Department of Molecular Biology and Center of Molecular Biology Severo Ochoa, Autonomous University of Madrid-C.S.I.C Campus Cantoblanco, Madrid, Spain; ${ }^{3}$ Department of Veterinary Clinical and Animal Sciences, Faculty of Health and Medical Sciences, University of Copenhagen, Grønnegaardsvej 7, 1870 Frederiksberg C, Denmark: ${ }^{4}$ BRIDGE - Brain Research Inter-Disciplinary Guided Excellence, Department of Clinical Research, University of Southern Denmark, J.B. Winsloewsvej 19, DK-5000 Odense C, Denmark

* Authors contributed equally to this work

Corresponding author:

Morten Meyer, Ph.D.

Department of Neurobiology Research

Institute of Molecular Medicine

University of Southern Denmark

J.B. Winsløws Vej 21, st

DK-5000 Odense C, Denmark

Telephone: +4565503802

E-mail: mmeyer@health.sdu.dk 


\begin{abstract}
Mutations in the PARK2 gene encoding parkin, an E3 ubiquitin ligase, are associated with autosomal recessive early-onset Parkinson's disease (PD). While parkin has been implicated in the regulation of mitophagy and proteasomal degradation, the precise mechanism leading to neurodegeneration in both sporadic and familial PD upon parkin loss-of-function mutations remains unknown. Cultures of isogenic induced pluripotent stem cell (iPSC) lines with and without PARK2 knockout (KO) enable mechanistic studies of the effect of parkin deficiency in human dopaminergic neurons. In the present study, we used such cells to investigate the impact of PARK2 $\mathrm{KO}$ on the lysosomal compartment combining different approaches, such as mass spectrometry-based proteomics, electron microscopy (TEM) analysis and functional assays. We discovered a clear link between parkin deficiency and lysosomal alterations. PARK2 KO neurons exhibited a perturbed lysosomal morphology, displaying significantly enlarged and electron-lucent lysosomes as well as an increased total lysosomal content, which was exacerbated by mitochondrial stress. In addition, we found perturbed autophagic flux and decreased lysosomal enzyme activity suggesting an impairment of the autophagylysosomal pathway in parkin-deficient cells. Interestingly, activity of the GBA-encoded enzyme, $\beta$-glucocerebrosidase, was significantly increased suggesting the existence of a compensatory mechanism. In conclusion, our data provide a unique characterization of the morphology, content, and function of lysosomes in PARK2 KO neurons, thus revealing a new important connection between mitochondrial dysfunction and lysosomal dysregulation in PD pathogenesis.
\end{abstract}




\section{Introduction}

Parkinson's disease (PD) is a progressive neurodegenerative disorder affecting 1-2\% of the population. Although the majority of PD patients develop late-onset sporadic disease, a subpopulation of patients develops early-onset or familial PD forms associated with various genetic mutations. Studies of the effects of these mutations can provide valuable insights into the molecular pathways and mechanisms that lead to degeneration of dopaminergic neurons in PD (1-4).

Mutations in the PARK2 gene, encoding the protein parkin, have been identified as the most common cause of autosomal recessive early-onset PD and have underlined the importance of mitochondrial dysfunction in PD pathogenesis (5-7). Parkin is a multifunctional E3 ubiquitin ligase involved in several cellular processes. Parkinmediated ubiquitination of mitochondrial proteins (8-11) triggers clearance of impaired mitochondria through the autophagy-lysosome pathway (ALP) (12). Lysosomes are organelles specialized for the degradation of macromolecules derived from the extracellular space through endocytosis or phagocytosis, or from the cytoplasm through autophagy. In recent years, the importance of lysosomes in pathology has been indicated by a rapidly growing number of human disorders linked to defects in lysosomal function including PD $(13,14)$ in which the accumulation of non-degraded and misfolded proteins occurs. Mutations in the GBA gene, coding for the lysosomal glycohydrolase $\beta$-glucocerebrosidase (GCase), cause Gaucher's disease and several studies have reported GBA mutations as the numerically greatest genetic risk factor for PD (15-17). A number of studies point to an interplay between mitochondrial homeostasis and proper lysosomal function. Diseases caused by mutations of ALP proteins often exhibit mitochondrial defects as well (18-20). Of relevance for PD, loss of GCase activity leads to mitochondrial dysfunction indicating that impaired lysosomal function negatively impacts mitochondria (17). Supporting this, autophagy enhancing drugs such as rapamycin has neuroprotective effects against the mitochondrial complex I inhibitor rotenone in cellular models of PD (21). Interestingly, mitochondrial dysfunction induced by rotenone treatment alters the expression of lysosomal genes, which perhaps is explained by the fact that mitophagy induction through nuclear translocation of transcription factors regulates mitochondrial and lysosomal biogenesis $(22,23)$. Recent studies have documented mitochondria-lysosome membrane contact sites, which enable 
bidirectional regulation of mitochondrial and lysosomal dynamics, and have demonstrated how mitochondrial impairment supresses autophagic flux, overall suggesting a complex mutual relationship between these two cellular compartments (2428).

However, the exact relationship between mitochondrial- and lysosomal function in PD is not well defined $(23,27,28)$ and elucidation of a potential link between them and its role in the pathogenic process is still required. By studying the lysosomal compartment and function in the context of parkin deficiency, we sought to address whether chronic mitochondrial dysfunction causes lysosomal impairment, contributing to PD pathogenesis. For this purpose, we studied isogenic iPSC-derived neuronal cultures with and without PARK2 mutation, which we have recently demonstrated lead to several mitochondrial defects (29). Parkin deficiency resulted in a number of perturbations including altered lysosomal content, morphology and function as well as impaired autophagic flux, indicating a connection between parkin deficiency and lysosomal disturbances. 


\section{Results}

\section{Identical differentiation potentials of $P A R K 2$ KO iPSCs and control lines}

To study the disease mechanism underlining PARK2-mediated PD, we analyzed two isogenic iPSC lines created from a healthy control iPSC line, where KO of the PARK2 gene was created by zinc finger nuclease gene editing technology (30). Detailed cell line information is reported in our recent study (29).

PARK2 $\mathrm{KO}$ and isogenic control iPSC-derived neuronal stem cells (NSCs) were differentiated simultaneously to assess the efficiency of midbrain dopaminergic neuron yield (Fig. 1A). Fig. 1B shows representative immunofluorescence pictures of cultures differentiated for 25 days, revealing a large percentage of MAP2+ mature neurons with distinct cell bodies and long branched processes forming highly interconnected networks. No apparent difference in the percentage of mature neurons was observed (control: $69.8 \pm 1.0 \%$, PARK2: $68.4 \pm 0.9 \%$ ) (Fig. 1C). The differentiated cells were also positive for NeuN and synaptophysin markers, which confirmed their maturity (Bogetofte et al., submitted). Many of the generated neurons were found to co-localize with the dopaminergic marker tyrosine hydroxylase $(\mathrm{TH})$, which is the rate-limiting enzyme in the production of dopamine. No apparent difference in the amount of $\mathrm{TH}+$ dopaminergic neurons was observed between cell lines (control: $25.25 \pm 1.0 \%, P A R K 2$ : $24.6 \pm 1.1 \%)($ Fig. 1D). Moreover, the presence of GABAergic + neurons and a small population of GFAP+ astrocytes was also found in the cultures (Bogetofte et al., submitted). Western blot analysis showed similar amounts of MAP2 and TH protein expression between control and PARK2 KO cell lines, confirming the immunofluorescence staining (Figs. $1 E, F$ ). qRT-PCR analysis detected the presence of midbrain dopaminergic specific markers (EN1, NURR1, GIRK2) in the differentiated neuronal cultures (Fig. 1G). Both lines showed comparable expression levels with no significant differences. These data show that PARK2 KO does not affect the neuronal differentiation potential of the iPSC-derived NSCs, as both the PARK2 KO and isogenic control lines were equally efficient in generating midbrain dopaminergic neurons.

\section{Proteomic changes and increased lysosomal content in PARK2 KO neurons}

As earlier reported we have subjected $P A R K 2 \mathrm{KO}$ and isogenic control neuronal cultures to a mass spectrometry-based proteomic analysis, which enabled the identification and quantification of a large number of proteins (29). Based on this recently published 
dataset (29) we detected significant changes in levels of 22 lysosomal proteins in PARK2 KO neurons (Table 1). A number of these proteins were of importance for vesicle-mediated protein trafficking through the endosomal-lysosomal system and for the ALP pathway (Table 1). This indicated that lysosomal perturbations were indeed present in the PARK2 KO neurons and led us to examine the overall lysosomal content of PARK2 KO neurons. Interestingly, levels of both lysosomal associated membrane protein 1 and 2a (LAMP1/2a), which are often used as general markers for lysosomes, were significantly elevated as quantified by Western blotting (Figs. $2 A, B$ ), pointing to an overall increased lysosomal content in the PARK2 KO neurons.

\section{TEM evidences for lysosomal abnormalities in PARK2 KO neurons}

To further investigate the lysosomal perturbations suggested by the proteomic analysis we applied transmission electron microscopy (TEM) analysis, which revealed several ultrastructural disturbances within lysosome-like structures. Lysosomes were identified as electron-dense small spherical organelles, enclosed by a single membrane, with a size of about 0.5-1.0 $\mu \mathrm{m}$ in diameter (31). Ultrastructural assessment of the PARK2 $\mathrm{KO}$ and healthy control neurons detected clear differences in lysosomal morphology between the two cell lines. Lysosomes in neurons with PARK2 KO were more heterogeneous and characterized by the presence of large translucent areas, whereas lysosomes from healthy control neurons more uniformly displayed an electron-dense inner compartment (Fig. 2C). Quantitative analysis of the number of lysosomes confirmed a significant accumulation of lysosomes in PARK2 $\mathrm{KO}$ neurons compared to healthy isogenic controls $(70 \%$ increase, $\mathrm{p}<0.01)($ Fig. $2 D)$. The area of the individual lysosomes was increased for PARK2 KO neurons by approximately $40 \%(\mathrm{p}<0.01)$ compared to controls (Fig. 2E). This verified the presence of enlarged lysosomal vacuoles observed for PARK2 KO neurons. In addition, the mean gray value (a measure of lysosomal electron density) was significantly reduced for PARK2 KO neurons (20\% decrease, $\mathrm{p}<$ 0.05) (Fig. 2F). This led us to categorize lysosomes into two groups: electron-lucent (lighter) and electron-dense (darker), and we found a significantly greater amount of electron-lucent lysosomes in the PARK2 KO neurons compared to controls (37.5\% vs. $24.8 \%$, respectively, $\mathrm{p}<0.01$ ) (Fig. 2G). Overall, TEM analysis revealed significant morphological changes in lysosomes between PARK2 KO neurons and isogenic control neurons. Lysosomal vacuoles appeared to be more abundant, larger and more electronlucent (lighter) in PARK2 KO neurons than in controls. 


\section{Altered lysosomal abundance in mature $P A R K 2$ KO neurons}

In order to investigate the time course of the lysosomal accumulation during the differentiation of PARK2 $\mathrm{KO}$ neurons, we investigated the abundance of lysosomes at different time points by immunofluorescence staining using the lysosomal marker LAMP1 (Figs. 3A-E). We did not observe significant differences in the pattern of LAMP1 staining between PARK2 $\mathrm{KO}$ and isogenic control neurons at the early stages of differentiation day 0 (neural stem cell stage) and 10 (progenitor cell stage) (Figs. 3A, $B, F)$. After 25 days of differentiation, when approximately $70 \%$ of the neurons were mature (Fig. 1C), PARK2 KO neurons contained significantly increased area of lysosomes per cell, consistent with the obtained TEM data. This was evident from an approximately $25 \%$ increase in the area of LAMP1+ staining per DAPI+ nuclei in PARK2 KO neurons compared to control neurons (Figs. 3C, F). The lysosomal area was increasing for both cell lines proportional to the time of differentiation, retaining the observed lysosomal accumulation in PARK2 KO neurons (Figs. 3A-F). Moreover, at the later stages of differentiation in healthy control neurons, lysosomes were well resolved as puncta (Figs. 3C-E, upper panel, white arrows). In contrast, lysosomes appeared enlarged and clustered in PARK2 KO cells (Figs. 3C-E, lower panel, red arrows). Altogether, our findings demonstrate that parkin dysfunction causes lysosomal accumulation and altered subcellular distribution in mature human PARK2 $\mathrm{KO}$ neurons in a time dependent manner.

\section{Increased lysosomal abundance after CCCP treatment}

To investigate whether the accumulation of lysosomes observed in PARK2 KO neurons at day 25 was a direct consequence of mitochondrial impairment we studied the lysosomal response to mitochondrial stress caused by carbonyl cyanide m-chlorophenyl hydrazine (CCCP), a proton ionophore that collapses the proton electrochemical gradient across membranes, thus acting as a potent uncoupler of respiratory chain function and oxidative phosphorylation (32). After 48 hours of CCCP (10 $\mu \mathrm{M})$ exposure, the area of lysosomes in control cells had increased to a level similar to that of PARK2 KO untreated neurons (41.8 vs. 40.15 arbitrary units, respectively, $\mathrm{p}=0.98$ ), strongly indicating that mitochondrial function impairment leads to lysosomal accumulation. Interestingly, CCCP treatment of PARK2 KO neurons resulted in further enhancement of LAMP1 staining (Figs. 3G,H), consistent with the hypothesized 
mitochondrial dysfunction present in these cells and indicating that this is a general consequence of mitochondrial dysfunction. Taken together, our data show that exposure to mitochondrial stressors, like CCCP, results in elevated lysosomal area in both PARK2 $\mathrm{KO}$ and healthy neurons, which provides further evidence of a causative link between mitochondrial dysfunction and lysosomal alterations.

\section{Perturbed lysosomal function and autophagic flux in PARK2 KO neurons}

To determine whether the alterations in lysosome protein levels and overall organelle structure may impact lysosomal function, we performed several functional assays. The first analysis assessed lysosomal intracellular activity (general enzyme activity) and revealed a significant $>30 \%$ reduction $(\mathrm{p}<0.05)$ in overall functional activity of lysosomes in PARK2 $\mathrm{KO}$ neurons compared to controls (Figs. 4A, B). To further investigate the impairment of lysosomal function, we additionally monitored the activity of two essential lysosomal enzymes, $\beta$-galactosidase ( $\beta$-Gal, Figs. $4 C, D)$ and $\beta$-glucocerebrosidase (GCase, Fig. 4E-G). $\beta$-Gal activity was linear over the assay time and a clear reduction was observed for the PARK2 $\mathrm{KO}$ neurons when compared to controls, which pattern was more similar to the positive control included in the assay (Fig. 4C). Moreover, the specific $\beta$-Gal activity was calculated, which confirmed a reduction of activity in the PARK2 KO neurons (control: $56 \pm 5.7$ enzymatic units, PARK2: $37.5 \pm 2.3$ enzymatic units, $\mathrm{p}<0.01)$ (Fig. 4D). Interestingly and in parallel, the activity of the lysosomal enzyme GCase, encoded by the PD-related $G B A$ gene, was significantly increased in the PARK2 KO neurons (approximately $25 \%$ increase, $\mathrm{p}<$ 0.001) (Fig. 4E). As the protein levels of GCase were not significantly increased (Fig. $4 F$ ), the enhanced GCase activity was not simply an effect of increased lysosomal numbers or enlargement. Rather it may reflect a compensatory functional activation (Figs. 4E-G). In order to establish if the alterations detected in the lysosomal function also affected the autophagic process, as alluded to by the proteomic analysis (Table 1), we analyzed through Western blotting the expression of microtubule-associated proteins 1A/1B light chain 3 (gene MAP1LC3A in Table 1), a known marker of autophagy (33). The total amount of LC3 protein was significantly decreased in PARK2 $\mathrm{KO}$ neurons at baseline confirming the results from the proteomic analysis (Table 1, Figs. 4H, 4I). LC3-II protein turnover was measured as the ratio between protein levels of LC3-II and LC3-I in the presence and absence of bafilomycin A1, which inhibits 
lysosomal acidification and fusion of autophagosomes with the lysosome. At baseline the PARK2 KO neurons compared to control had a significantly increased LC3-II/LC3I ratio, which however was unaffected by bafilomycin A1 treatment. In contrast the control neurons showed a significant increase in the LC3-II/LC3-I ratio upon bafilomycin A1 treatment (Figs. 4H, 4J). This indicates that autophagy induction is occurring, but that in the PARK2 $\mathrm{KO}$ neurons the autophagic process is stalled due to lysosomal impairment. Overall, the PARK2 $\mathrm{KO}$ neurons showed a significantly decreased autophagy process compared to healthy control neurons (approximately $30 \%$ decrease, $\mathrm{p}<0.01)($ Fig. $4 K)$. In conclusion, these data overall provide strong and consistent evidence of a perturbed lysosomal activity and compromised autophagic flux in the PARK2 KO neurons. 


\section{Discussion}

The importance of parkin dysfunction in familial and sporadic PD is well established, but the exact mechanism and pathways are not well understood $(6,33)$. Parkin was associated with mitochondrial function for the first time through studies in Drosophila M. (34). However, today we know that the parkin protein has multiple roles and that it is crucial for the proper function of not only mitochondria but also lysosomes $(23,34)$. A common feature shared by these two organelles is that mitochondrial defects and lysosomal function impairment can lead to neurological pathologies, suggesting functional connections between these two organelles $(35,36)$.

In our recent report we demonstrated prominent mitochondrial-related defects and the mitochondrial proteome perturbations (29) in response to parkin deficiency. Therefore, to explore the reciprocal relationship between mitochondrial and lysosomal pathways in $\mathrm{PD}$, in the present study we investigated the impact of parkin dysfunction on lysosome structure and function by applying human iPSC-derived neurons with PARK2 mutations and isogenic healthy control. We identified striking differences in lysosomal abundance, morphology, content and activity in the PARK2 KO neurons. Endolysosomal alterations have been documented in other parkin dysfunction models (37, 38). However, to our knowledge, this is the first experimental evidence obtained from human PARK2 KO iPSC-derived neurons.

One of the consequences of mitochondrial deficits caused by parkin dysfunction in this cellular model of PD was an increased lysosomal number and size. This altered phenotype appeared at differentiation day 25 , when the cells also exhibit aberrant mitochondria, indicating increased vulnerability of mature neurons (29). Similar lysosomal alterations to those observed in our study were detected in mitochondrial mutants exhibiting disrupted mitochondrial fission-fusion processes and cristae structure and mitochondrial impairment (27,39-41). A recent study in mice and cellular models of mitochondrial dysfunction reported a ROS-dependent increase in numbers of lysosomal vacuoles, suggesting a possible mechanism (27). Mitochondrial activity is required to maintain proper lysosomal structure and function, as demonstrated by studies applying chemical inhibition of the electron transport chain, as well as in in vitro and in vivo genetic models of mitochondrial dysfunction. Specifically, disruption 
of mitochondrial function causes the accumulation of enlarged endo-lysosomal structures $(27,39,42,43)$.

Our study supports these observations, as lysosomal numbers were increased following uncoupling of mitochondrial function by CCCP treatment in both neuronal populations. CCCP-treated control neurons contained almost equal numbers of lysosomes as PARK2 $\mathrm{KO}$ untreated neurons, pointing to an association between lysosomal accumulation and mitochondrial membrane depolarization caused by CCCP. In line with this, an increase in lysosomal number was found in HeLa cells following treatment with the electrogenic ionophore agents CCCP and valinomycin (44). Recently, acute CCCP treatment was found to promote lysosomal biogenesis through activation of transcription factor EB (TFEB) $(23,45)$. TFEB regulates both mitochondrial and lysosomal biogenesis and is translocated to the nucleus upon starvation, mitophagy induction and when lysosomal function is impaired (46-48). Whether TFEB translocation/activation is responsible for the increased lysosomal content in PARK2 KO neurons remains to be examined.

Another contributing factor to the increased lysosomal content in PARK2 KO neurons could be an impaired lysosomal degradation capacity and the build-up of undegraded cargo, as reported in iPSC-derived dopaminergic neurons from GBA patients $(47,49)$. Applying TEM we detected an increased number of large electron-lucent lysosomes in PARK2 KO neurons. These less electron-dense lysosomes might represent lysosomes in which digestion of the contents is perturbed, as the normally dark lumen is a result of enzymes actively degrading the material in acidic lysosomal interior (31). Similar observations of enlarged and electron-lucent lysosomal vacuoles are described in lysosomal storage disorders (50-52). Supporting this notion, the overall lysosomal enzyme activity was significantly decreased in the PARK2 KO neurons. A recent study on cellular models of mitochondrial dysfunction induced by chemical stressors or deletion of mitochondrial proteins including PINK1, also documented impaired lysosomal enzyme activity. These changes were dependent on ROS levels, as antioxidant treatment could revert the observed phenotypes (27). Given that the PARK2 KO neurons have decreased levels of antioxidant defense enzymes (29), a similar mechanism could be relevant in the observations made in the present study.

The impaired lysosomal enzyme activity found here is a likely cause of the compromised autophagic flux in the PARK2 KO neurons. However, as indicated by the 
proteomic data perturbations in levels of proteins involved in the autophagic process including LC3, which was significantly decreased, were also present. Decreased autophagic flux has similarly been documented in a recent study performed on PARK2PD fibroblasts as well as in iPSC-derived neurons from GBA- and sporadic PD patients $(47,53,54)$.

Interestingly, the GCase activity was significantly increased in the PARK2 $\mathrm{KO}$ neurons whereas activity of $\beta$-Gal and overall lysosome enzymatic activity were reduced. This points to the activation of a compensatory mechanisms to increase GCase activity, as the total protein level of GCase was unchanged. A direct interaction between parkin and GCase could explain such link, as parkin can directly interact with and mediate degradation of mutant GCase (55). However, this was not the case for wildtype GCase and further studies are needed in order to address the interplay between GCase activity and parkin disfunction.

In conclusion, our results indicate that the loss of PARK2 causes several lysosomal perturbations affecting their abundance, morphology, content and activity. Taken together with our previous data, these findings contribute to causally link two major pathological features of PD, namely mitochondrial defects and lysosomal dysregulation, supporting the idea of a direct pathogenic positive feedback between the two organelles. Future efforts must be focused on the identification of the molecular mechanistic pathways connecting mitochondrial and lysosomal perturbations with the aim of developing therapeutic approaches for PD. 


\section{Acknowledgements}

This work was supported by the Innovation Fund Denmark (BrainStem), H. Lundbeck A/S, the Danish Parkinson Foundation, the A.P. Møller Foundation for the Advancement of Medical Science, and the Faculty of Health Sciences at University of Southern Denmark. Work at the A.M.S. group at the CBMSO-Madrid was supported by grants from MINECO SAF-2017-83241-R, and ISC-III RETICS TerCel RD16/0011/0032.

The live imaging experiments reported in this paper were performed at DaMBIC, a bioimaging research core facility at the University of Southern Denmark. DaMBIC was established by an equipment grant from the Danish Agency for Science Technology and Innovation and by internal funding from the University of Southern Denmark. $(+$ Clair Gudex)

The authors would like to thank Dorte Lyholmer, Nadine Nadine Becker-von Buch, Ulla Melchior Hansen and Maria Pihl for excellent technical assistance. 


\section{Materials and Methods}

\section{CCCP (cyanide m-chlorophenylhydrazone) and BAF (bafilomycinA1) treatments}

$20 \mathrm{mM}$ stock solution of CCCP (Sigma-Aldrich) was prepared by dissolving in DMSO (Sigma-Aldrich) and further diluted to get a final concentration of $10 \mu \mathrm{M}$. Cells were treated with CCCP or with equivalent dose of vehicle (DMSO) for 48h. CCCP solution was prepared on the day of the experiment and was protected from light.

Bafilomycin A1 (Sigma-Aldrich) was dissolved in DMSO (Sigma-Aldrich). Cells were treated with $10 \mathrm{nM}$ bafilomycin $\mathrm{A} 1$ or with equivalent dose of vehicle (DMSO) for $6 \mathrm{~h}$.

\section{In vitro propagation and differentiation of neural stem cells (NSCs)}

$P A R K 2 \mathrm{KO}$ and healthy isogenic control NSC cell lines were provided by XCell Science Inc. (CA, USA). NSC lines were propagated according to well-established and standard protocol, using Geltrex-(Thermo Fisher) coated plates in Neurobasal Medium (Thermo Fisher) supplemented with NEAA, GlutaMax-I, B27, supplement (Thermo Fisher), penicilin-streptomycin, and bFGF. Cells were enzymatically passaged with Accutase (Thermo Fisher) when reaching 80-90\% confluency. NSCs were differentiated according to a commercially available dopaminergic differentiation kit (\#DD-001) from XCell Science Inc. (CA, USA). Differentiation was divided in two parts: an induction phase, where NSCs were differentiated into dopaminergic precursors and a maturation phase, where the dopaminergic precursor cells were differentiated into mature dopaminergic neurons. The differentiations were carried out at $37^{\circ} \mathrm{C}$ in a low $\mathrm{O}_{2}$ environment $\left(5 \% \mathrm{CO}_{2}, 92 \% \mathrm{~N}_{2}\right.$ and $\left.3 \% \mathrm{O}_{2}\right)$. The cells were seeded onto poly-Lornithine (Sigma) and laminin- (Thermo Fisher)coated wells at the density of 50.000 cells $/ \mathrm{cm}^{2}$. Complete DOPA Induction Medium (XCell Science) supplemented with 200 $\mathrm{ng} / \mathrm{ml}$ human recombinant Sonic Hedgehog (Peprotech) was changed every second day for the first 9 days of differentiation. The cells were passaged at day 5 and 10 and seeded at a desired cell density. The medium was switched to Complete DOPA Maturation Medium A and B (XCell Science) at day 10 and 16, respectively.

\section{Quantitative Polymerase Chain Reaction (qPCR)}

Cell lysates were analyzed by qPCR for the mRNA expression of the dopaminergic markers EN1, NURR1 and GIRK2. Medium was aspirated from the wells and $500 \mu 1$ 
cold Trizol lysis reagent (Life Technologies) was added per well. Cells were harvested using a sterile cell scraper and transferred to RNase-free eppendorf tubes. Samples were vortexed for $30 \mathrm{~min}$ to completely lyse the cells. RNA purification was performed through columns according to manufacturer's instructions (ENZA total RNA Kit I, VWR). Reverse transcription from mRNA to cDNA was performed using the Super Script III reverse transcriptase kit (Invitrogen) according to manufacturer's instruction. cDNA was processed by qPCR analysis using a protocol customized according to the instructions of the SsoFastTM EvaGreen ${ }^{\circledR}$ Supermix (BioRad) in the BioRad CFX-96 equipment. The efficiency of all primer sets was tested prior to qPCR analysis. For that, cDNA from a positive control (iPSC-derived midbrain dopaminergic neurons, day 30 of differentiation) was tested in 4 different concentrations: 1:1, 1:2, 1:5 and 1:10 and the efficiency assessed using the BioRad software. Acceptable range was defined as $100 \% \pm 10$. For specificity testing, the positive control and a negative iPSC control were included in the analysis. The expression level of the dopaminergic markers was quantified relative to the expression of the three housekeeping genes GAPDH, 18S, HPRT. Relative gene expression was assessed using the following TagMan assays: GAPDH, Hs02758991_g1; 18S, Hs03003631_g1; HPRT, Hs02800695_m1; EN1, Hs00154977_m1; NURR1, Hs00428691_m1; GIRK2, Hs00158423_m1.

\section{Cell collection for mass spectrometry-based proteomic}

PARK2 $\mathrm{KO}$ and control neuronal cultures from 3 independent differentiations were collected on ice in phosphate-buffered saline (PBS, ThermoFisher) with protease(Complete tablets, Roche) and phosphatase inhibitors (PhosSTOP tablets, Roche). The QProteome Mitochondria Isolation Kit (Qiagen \#37612) was used according to the manufacturer's instruction for standard preparation.

\section{Lysis, reduction and enzymatic digestion}

Samples were sonicated for two times ten seconds at 50\% amplitude on ice and incubated for $30 \mathrm{~min}$ at room temperature (RT) in lysis buffer consisting of $6 \mathrm{M}$ urea (Sigma), $2 \mathrm{M}$ thiourea (Sigma), $20 \mathrm{mg} / \mathrm{ml}$ sodium dodecyl sulfate (SDS, GE Healthcare), $40 \mathrm{nM}$ N-ethylmaleimide (NEM, Sigma) and protease inhibitor. The proteins were denatured and reduced in $6 \mathrm{M}$ urea, $2 \mathrm{M}$ thiourea and $10 \mathrm{mM}$ TCEP (Thermo Fisher) at RT. After vortexing, the samples were incubated at RT for 2 hours with $1 \mu$ endoproteinase Lys-C (Wako). The samples were diluted 10 times in $20 \mathrm{mM}$ 
TCEP and $20 \mathrm{mM}$ tetraethylammonium bromide (TEAB, Sigma), pH 7.5, and sonicated followed by digestion with $1 \mu \mathrm{g}$ trypsin (Sigma) per $50 \mu \mathrm{g}$ peptide over night (ON) at RT.

\section{Desalting, Tandem Mass Tag labelling and enrichment of phosphorylated peptides}

The samples were acidified with $0.1 \%$ trifluoroacidic acid (TFA, Sigma) and desalted using two self-made P200-tip-based columns per sample. $45 \mu \mathrm{g}$ of each sample were labeled with Tandem Mass Tag (TMT) Sixplex Isobaric label Reagents (ThermoFisher) according to the manufacturer's instructions. Efficient labeling was confirmed by MALDI, and the labeled peptides mixed 1:1:1:1:1:1 and dried.

\section{Hydrophobic interaction liquid chromatography (HILIC) and high pH fractionation}

Mono-phosphorylated and non-modified peptides were fractionated to reduce sample complexity using HILIC. To increase the coverage, high $\mathrm{pH}$ fractionation was also performed using approximately $50 \mu \mathrm{g}$ peptide of the non-modified peptide sample. Briefly, the sample was dissolved in $1 \%$ ammonium hydroxide $\left(\mathrm{NH}_{3}\right.$, Sigma), $\mathrm{pH} 11$, and loaded on a $\mathrm{R} 2 / \mathrm{R} 3$ column equilibrated with $0.1 \% \mathrm{NH}_{3}$. The peptides were eluted in a stepwise fashion using a gradient of $5 \%-60 \% \mathrm{ACN} / 0.1 \% \mathrm{NH}_{3}$. All fractions were dried by vacuum centrifugation.

\section{Reversed-phase nano LC-ESI-MS/MS}

The samples were resuspended in $0.1 \%$ formic acid (FA) and loaded onto a two-column EASY-nLC system (Thermo Scientific). The pre-column was a $3 \mathrm{~cm}$ long fused silica capillary (100 $\mu \mathrm{M}$ inner diameter) with a fritted end and in-house packed with ReproSil - Pur C18 AQ $5 \mu \mathrm{m}$ (Dr. Maisch GmbH) whereas the analytical column was a $17 \mathrm{~cm}$ long fused silica capillary (75 $\mu \mathrm{m}$ inner diameter) and packed with ReproSil-Pur C18 AQ $3 \mu \mathrm{m}$ reversed-phase material (Dr. Maisch $\mathrm{GmbH}$ ). The peptides were eluted with an organic solvent gradient from $100 \%$ phase A $(0.1 \%$ FA) to $34 \%$ phase B $(95 \%$ ACN, $0.1 \% \mathrm{FA}$ ) at a constant flowrate of $250 \mathrm{~nL} / \mathrm{min}$. Depending on the samples based on the HILIC, the gradient was from 1 to $30 \%$ solvent B in $60 \mathrm{~min}$ or $90 \mathrm{~min}, 30 \%$ to $50 \%$ solvent B in $10 \mathrm{~min}, 50 \%-100 \%$ solvent $\mathrm{B}$ in $5 \mathrm{~min}$ and $8 \mathrm{~min}$ at $100 \%$ solvent $\mathrm{B}$. The 
nLC was online connected to a QExactive HF Mass Spectrometer (Thermo Scientific) operated at positive ion mode with data-dependent acquisition. The Orbitrap acquired the full MS scan with an automatic gain control (AGC) target value of $3 \times 10^{6}$ ions and a maximum fill time of 100ms. Each MS scan was acquired at high-resolution $(120,000$ full width half maximum (FWHM)) at $\mathrm{m} / \mathrm{z} 200$ in the Orbitrap with a mass range of 400-1400 Da. The 12 most abundant peptide ions were selected from the MS for higher energy collision-induced dissociation (HCD) fragmentation (collision energy: 34V). Fragmentation was performed at high resolution (60,000 FWHM) for a target of $1 \times 10^{5}$ and a maximum injection time of $60 \mathrm{~ms}$ using an isolation window of $1.2 \mathrm{~m} / \mathrm{z}$ and a dynamic exclusion. All raw data were viewed in Thermo Xcalibur v3.0.

\section{Mass spectrometry data analysis}

The raw data were processes using Proteome Discoverer (v2.1, ThermoFisher) and searched against the Swissprot human database using an in-house Mascot server (v2.3, Matrix Science Ltd.) and the Sequest HT search engine. Database searches were performed with the following parameters: precursor mass tolerance of $10 \mathrm{ppm}$, fragment mass tolerance of 0.02 Da (HCD fragmentation), TMT 6-plex (Lys and Nterminal) as fixed modifications and a maximum of 2 missed cleavages for trypsin. Variable modifications were NEM on Cys and N-terminal acetylation along with phosphorylation of Ser/Thr/Tyr for the phosphorylated group. Only peptides with up to a q-value of 0.01 (Percolator), Mascot rank 1 and cut-off value of Mascot score $>15$ were considered for further analysis. Only proteins with more than one unique peptide were considered for further analysis in the non-modified group.

\section{Sample preparation for transmission electron microscopy (TEM)}

The TEM sample preparation procedure included five major steps: fixation, dehydration, infiltration and embedding, sectioning, and contrasting. Cells were seeded on $13 \mathrm{~mm}$ Thermanox plastic coverslips (Nunc) with a density of 80.000 cells $/ \mathrm{cm}^{2}$. At day 25 of differentiation cell were primarily fixed in 3\% gluteraldehyde (Merck) in 0.1 $\mathrm{M}$ Natrium phosphate buffer with $\mathrm{pH} 7.2$ at $4^{\circ} \mathrm{C}$ for $1 \mathrm{~h}$ and stored in a $0.1 \mathrm{M} \mathrm{Na}$ phosphate buffer at $4^{\circ} \mathrm{C}$ until further analysis. When ready, the cells were embedded in $4 \%$ agar at $45^{\circ} \mathrm{C}$ (Sigma) under the stereomicroscope and cut into $1-2 \mathrm{~mm}^{3}$ blocks, which were then washed with 0.1 Na-phosphate buffer, followed by a post-fixation in $1 \%$ osmium tetroxide (EMS) in 0.1 Na-phosphate buffer $(\mathrm{pH} 7.2)$ for $1 \mathrm{~h}$ at RT. Cells 
were washed in MilliQ water, followed by a stepwise dehydration in a series of ascending ethanol concentrations ranging from 50\% EtOH to $99 \%$ EtOH). Then propylene oxide (Merck) was used as an intermediate allowing for infiltration with Epon (812 Resin, TAAB). The following day, the agar blocks were placed in flat molds in pure Epon, which was cured at $60^{\circ} \mathrm{C}$ for $24 \mathrm{~h}$. Approximately 8 semi-thin sections $(2$ $\mu \mathrm{m})$ from one block were cut on an ultramicrotome with glass knife (Leica, Reichert Ultracut UTC). These were stained with 1\% toluidine blue in 1\% Borax and evaluated by light microscopy to locate areas with adequate number of cells for further processing. Ultra-thin sections $(70 \mathrm{~nm})$ were cut on the ultramicrotome with a diamond knife (Jumdi, $2 \mathrm{~mm}$ ), and the ultra-thin sections were collected onto TEM copper grids (Gilder), and then stained with 2\% uranyl acetate (Polyscience) and lead citrate (Reynolds 1963). The samples were then evaluated and the image database collected using a Philips CM100 transmission electron microscope equipped with a Morada digital camera equipment and iTEM software system.

\section{Measurements of lysosomal numbers on TEM images}

Six TEM grids from each line were used for analysis, and at low magnification 10 spots were randomly chosen. Images of each spot were captured using high magnification (19.000X). To estimate lysosomal number, all lysosomes were counted on each micrograph. For further morphometric analysis individual organelles were selected and processed manually using the different selection tools in ImageJ software.

\section{Western blotting}

Cell lysates were analyzed by sodium dodecyl sulphate polyacrylamide gel electrophoresis (SDS-PAGE) to separate the proteins by molecular weight followed by western blotting. Cells were differentiated in 6-well plates (Costar) with a cell density of 50.000 cells $/ \mathrm{cm}^{2}$ and harvested using accutase. Cell pellets were resuspended in PBS containing phosphatase (PhosphoSTOP tablet, Roche) and protease inhibitors (Complete Mini Tablets, Roche) on ice. Sample were centrifuged (10.000 rpm, $5 \mathrm{~min}$, $4^{\circ} \mathrm{C}$ ), supernatant aspirated and cells sonicated for $2 \times 10 \mathrm{sec}$ at amplitude 2 , low speed on ice in PBS containing phosphatase and protease inhibitors supplemented with $1 \%$ Triton X-100. Afterwards, samples were incubation for $30 \mathrm{~min}$ at $4{ }^{\circ} \mathrm{C}$ with shaking and then centrifuged $\left(10.000 \mathrm{rpm}, 15 \mathrm{~min}, 4^{\circ} \mathrm{C}\right)$ and the supernatants were collected. The protein content in the samples was determined using the Micro Pierce ${ }^{\circledR}$ Bicinchoninic 
acid (BCA) Protein Assay (Thermo Scientific). Prior to electrophoresis, equal amounts of protein from each sample were mixed 1:1 with NuPAGE reducing loading buffer and denatured for $10 \mathrm{~min}$ at $70^{\circ} \mathrm{C}$. For detection of TH $20 \mu \mathrm{l}(5 \mu \mathrm{g}$ protein)/well sample and $10 \mu \mathrm{l} /$ well SeeBlue Plus2® prestained standard (Novex) were loaded on $4-12 \%$ Bis/Tris gels (Invitrogen NuPAGE). Electrophoresis was performed with NuPAGE MOPS SDS running buffer (Invitrogen NuPAGE) supplemented with $0.25 \%$ antioxidant (Invitrogen NuPAGE) for $50 \mathrm{~min}$ at $200 \mathrm{~V}$. For detection of MAP2 $20 \mu \mathrm{l}(5 \mu \mathrm{g}$ protein)/well sample and $10 \mu \mathrm{l} /$ well HiMark prestained standard (Novex) were loaded on 3-8\% Tris-Acetate gels (Invitrogen NuPAGE). Electrophoresis was performed with Tris-Acetate SDS running buffer (Invitrogen NuPAGE) supplemented with $0.25 \%$ antioxidant for $60 \mathrm{~min}$ at $150 \mathrm{~V}$. Proteins were blotted from the gels to PVDF membranes (Invitrogen) using the IBlotTM Dry blotting system from Invitrogen. Blotting was performed for $7 \mathrm{~min}$ for $\mathrm{TH}$ and $9 \mathrm{~min}$ for MAP2. Membranes were blocked for $60 \mathrm{~min}$ in 5\% milk powder and $0.05 \%$ Tween-20 in $0.05 \mathrm{M} \mathrm{TBS}$ at $4^{\circ} \mathrm{C}$. After a short wash in $0.05 \%$ Tween- 20 in $0.05 \mathrm{M}$ TBS, the membranes were incubated ON with primary antibodies and the following dilutions were used: mouse anti-TH (\#MAB5280 Chemicon/Millipore) 1:2000, mouse anti-MAP2a+b (\#M1406, Sigma) 1:500, rabbit anti-LAMP1 (Abcam \#24170) 1:500, rabbit anti-LAMP2a (Abcam \#18528) 1:500, rabbit anti-GBA (Abcam \#154856) 1:1000, and rabbit anti-LC3 (Cell Signaling \#4599) 1:1000. After incubation with primary antibodies, the blots were washed 4 times in $0.05 \%$ Tween-20 in $0.05 \mathrm{M}$ TBS for $5 \mathrm{~min}$ at RT to remove unbound primary antibodies. Subsequently, blots were incubated with an appropriate horseradish peroxidase (HRP)-conjugated secondary antibody (\#P0260 or \#P0217, DAKO) with dilution 1:2000 for 1h at RT. Unbound secondary antibodies were afterwards removed by washing the blots 4 times in $0.05 \%$ Tween-20 in $0.05 \mathrm{M}$ TBS for $5 \mathrm{~min}$ at RT, followed by chemiluminescence development (ECL kit, ThermoFisher Scientific) and visualization using the ChemiDoc MP imaging system (BioRad). As loading control, all blots were subsequently incubated with $\alpha$-actin antibody (mouse anti- $\alpha$-actin, \#MAB1501, Chemicon/Millipore; $1: 6000) \mathrm{ON}$ at $4^{\circ} \mathrm{C}$ and developed as described above. Densitometric analyses of band intensities were quantified using Image Lab software (BioRad) and protein expression levels were normalized to $\alpha$-actin.

\section{Immunofluorescence staining}

Cells cultured on coverslips in 24-well plates (Costar) were fixed in $4 \%$ 
paraformaldehyde (PFA, Sigma) in 0.15 M Sørensen buffer (potassium dihydrogen phosphate (Merck) and disodium phosphate (Merck)) for 20 min at RT and then washed 2 times in $0.15 \mathrm{M}$ Sørensen Buffer for $15 \mathrm{~min}$. Fixed cells were washed once in $0.05 \mathrm{M}$ Tris Buffered Saline (TBS, Sigma) for $5 \mathrm{~min}$ at RT and then permeabilized by washing 3 times in $0.1 \%$ Triton X-100 (Sigma) in 0.05 M TBS for 15 min at RT, followed by blocking in 5\% goat serum (Millipore) in $0.05 \mathrm{M}$ TBS for $30 \mathrm{~min}$ at RT to avoid nonspecific binding of the primary antibodies. Afterwards, primary antibodies diluted in $5 \%$ goat serum were added to the cells and incubated $\mathrm{ON}$ at $4^{\circ} \mathrm{C}$. Primary antibodies were used in the following concentrations: rabbit anti-tyrosine hydroxylase $(\mathrm{TH}$, Millipore \#AB152) 1:600, mouse anti-microtubule-associated protein 2a+b (MAP2, Sigma \#M1406) 1:2000, rabbit anti-LAMP1 (Abcam \#108597) 1:1000. After ON incubation with primary antibody, cells were washed 3 times in $0.1 \%$ Triton X-100 in $0.05 \mathrm{M}$ TBS for $15 \mathrm{~min}$ at RT to remove unbound primary antibodies. The cells were then incubated with fluorophore-conjugated secondary antibodies: Alexa Fluor 488 goat anti-rabbit IgG (Invitrogen \#A11008) or Alexa Fluor 555 goat anti-rabbit IgG (Abcam \#150078) 1:500 diluted in 5\% goat serum in $0.05 \mathrm{M}$ TBS for $2 \mathrm{~h}$ at RT. Unbound secondary antibodies were afterwards removed by washing the cells 2 times in $0.05 \mathrm{M}$ TBS for $15 \mathrm{~min}$ at RT. Cells were then counterstained with $10 \mu \mathrm{M}$ Hoechst (Sigma) for 15 min at RT to stain all nuclei. Finally, cells were mounted onto glass slides using ProLong ${ }^{\circledR}$ Diamond mounting medium (Molecular Probes).

\section{Image analysis}

Fluorescence images were acquired on a FluoView FV1000MPE - Multiphoton Laser Confocal Microscope (Olympus) 20X or 60X magnification, in a blinded manner on 5 randomly chosen confocal fields per coverslip from independent experiments. $\mathrm{TH}+$ dopaminergic neurons and MAP2+ mature neurons stainings were quantified manually in Image J using the Cell Counter plugin and normalized to total cell numbers as quantified by DAPI+ nuclei analysis in CellProfiler software. Only cells displaying an extensive immunostaining with a well-preserved cellular morphology were counted. Analysis lysosomal numbers was performed automatically in ImageJ software by converting LAMP1 images to binary format and analyzing particles. Total area of lysosomes was normalized to total cell numbers as quantified by DAPI+ nuclei analysis in ImageJ software. 


\section{GCase activity assay}

Cell pellets were sonicated at $10 \mathrm{amp}$ for $10 \mathrm{sec}$ in citrate phosphate buffer $\mathrm{pH} 5.4$ consisting of $0.1 \mathrm{M}$ citric acid (Sigma) and $0.2 \mathrm{M}$ dibasic sodium phosphate (Sigma) with $0.25 \%(\mathrm{v} / \mathrm{v})$ Triton $\mathrm{X}$ and $0.25 \%(\mathrm{w} / \mathrm{v})$ taurocholic acid (Sigma). Samples were centrifuged at $800 \mathrm{~g}$ for $5 \mathrm{~min}$ at $4^{\circ} \mathrm{C}$ and supernatant collected. Following protein determination equal amounts of protein from each sample were diluted in citrate phosphate buffer in quadruplicates. One replicate of each sample was treated with 1 $\mathrm{mM}$ conduritol $\mathrm{B}$ epoxide (CBE, Calbiochem) for $10 \mathrm{~min}$ before all samples were incubated for $1 \mathrm{~h}$ with $2.5 \mathrm{mM}$ of the fluorescent GCase substrate methylumbillifery $\beta$ D-glucopyranoside (4MUG, Sigma) at $3^{\circ} \mathrm{C}$ in the dark. The reaction was quenched with $1 \mathrm{M}$ glycine buffer (Sigma) $\mathrm{pH} 10.8$ and the fluorescent levels analyzed on the PHERAStar FSX plate reader (BMG Labtech). Values from CBE-treated wells were subtracted as background.

\section{Total Lysosomal Intracellular Activity Assay}

Measurement of the total lysosomal intracellular activity was performed using Lysosomal Intracellular Activity Assay Kit (Cell-Based) (BioVision) according to manufacturer's protocol. Briefly, cells were plated on $13 \mathrm{~mm}$ glass coverslips in a 24well culture plate $\left(40.000\right.$ cells $\left./ \mathrm{cm}^{2}\right)$. Prior to the analysis the cells were incubated for $8 \mathrm{~h}$ in medium supplemented with $10 \% \mathrm{FBS}$ at $37^{\circ} \mathrm{C}$. Then the media was removed and replaced with fresh aliquots supplemented with 0.5\% FBS. $15 \mu 1$ of Self-Quenched Substrate was added per $1 \mathrm{ml}$ of media into each well and the plate incubated for $1 \mathrm{~h}$ at $37^{\circ} \mathrm{C} .10 \mathrm{~min}$ before the end of incubation 1:1000 Hoechst solution (Sigma) was added to each well to stain nuclei. After incubation the cells were analyzed under fluorescence microscope with $488 \mathrm{~nm}$ excitation filter to visualize the fluorescence of released SelfQuenched Substrate, which proportional to the total lysosomal intracellular activity. Fluorescence images were acquired on a FluoView FV1000MPE - Multiphoton Laser Confocal Microscope (Olympus) 60X magnification, in a blinded manner on 5 randomly chosen confocal fields per coverslip from independent experiments. Analysis was performed automatically in Image J software by converting images to binary format and analyzing particles. Total area of the staining was normalized to total cell numbers as quantified by Hoechst + nuclei analysis in ImageJ software. 


\section{Beta Galactosidase ( $\beta$-Gal) Assay}

Measurement of $\beta$-Gal activity was performed using Fluorometric Beta Galactosidase Activity Assay Kit (BioVision) according to manufacturer's protocol. Briefly, cells were plated in a 6-well plate $\left(60.000\right.$ cells $\left./ \mathrm{cm}^{2}\right)$ and homogenized with on ice with 100 $\mu 1$ ice cold $\beta$-Gal Assay Buffer and kept on ice for $10 \mathrm{~min}$. Cell lysates were transferred to eppendorf tubes and centrifuged at $10.000 \mathrm{~g}, 4^{\circ} \mathrm{C}$ for $5 \mathrm{~min}$, and subsequently supernatant was collected to a new eppendorf tubes. $30 \mu 1$ of supernatant in triplicates was transferred into desired wells in a 96-well black plate. For Positive Control the $\beta$ Gal Positive Control was diluted 1:25 in the Assay Buffer and mixed well. $15 \mu \mathrm{l}$ in triplicates of diluted $\beta$-Gal Positive Control was added into desired wells. The volume of samples and Positive Control wells was adjusted to $50 \mu 1 /$ well with $\beta$-Gal Assay Buffer. Required amount of Reaction Mix was prepared, containing $\beta$-Gal Assay Buffer and $\beta$-Gal Substrate and added to each well in volume of $50 \mu$ l. Fluorescence signal $(\mathrm{Ex} / \mathrm{Em}=480 / 520 \mathrm{~nm})$ was measured in kinetic mode and the Fluorescein Standard Curve was read in Endpoint mode.

\section{Autophagic Flux}

To examine the autophagic flux, we determined if LC3 is degraded in a lysosomaldependent manner by using bafilomycin A1, an inhibitor of lysosomal acidification but also, independently of its effect on lysosomal $\mathrm{pH}$, of fusion between autophagosomes and lysosomes. To this purpose, differentiated neurons were incubated with DMSO (untreated) or with medium containing bafilomycin A1 (10 nM for $6 \mathrm{~h}$ ). Western blot analysis was performed on cell lysates using antibodies against LC3 (Cell Signaling) and $\alpha$-actin (Abcam). The ratio between LC3-II and LC3-I was calculated and normalized to $\alpha$-actin, through densitometric analysis using ImageJ software, and the autophagic flux was calculated as the ratio of LC3-II of cells treated with bafilomycin A1 and untreated cells.

\section{Statistical analysis}

Statistical analysis was performed in GraphPad Prism 7.0 software using two-tailed unpaired Student's t-test and one-way ANOVA with Tukey's Multiple Comparison Test where appropriate. Data were considered statistically significant at $\mathrm{p}<0.05\left(^{*}\right), \mathrm{p}<0.01$ $(* *)$ and $\mathrm{p}<0.001(* * *)$. Data are presented as mean \pm standard error of the mean (SEM). 
bioRxiv preprint doi: https://doi.org/10.1101/734244; this version posted August 13, 2019. The copyright holder for this preprint (which was not certified by peer review) is the author/funder, who has granted bioRxiv a license to display the preprint in perpetuity. It is made available under aCC-BY-NC-ND 4.0 International license. 


\section{References}

1. Hardy J. Genetic analysis of pathways to Parkinson disease. Neuron. 2010;68(2):201-6.

2. Schapira AH. Etiology and pathogenesis of Parkinson disease. Neurol Clin. 2009;27(3):583-603, v.

3. Schapira AH, Jenner P. Etiology and pathogenesis of Parkinson's disease. Mov Disord. 2011;26(6):1049-55.

4. Caviness JN. Pathophysiology of Parkinson's disease behavior--a view from the network. Parkinsonism Relat Disord. 2014;20 Suppl 1:S39-43.

5. Arkinson C, Walden H. Parkin function in Parkinson's disease. Science. 2018;360(6386):267-8.

6. Dawson TM, Dawson VL. The role of parkin in familial and sporadic Parkinson's disease. Mov Disord. 2010;25 Suppl 1:S32-9.

7. Gasser T. Molecular pathogenesis of Parkinson disease: insights from genetic studies. Expert Rev Mol Med. 2009;11:e22.

8. Gegg ME, Cooper JM, Chau KY, Rojo M, Schapira AH, Taanman JW. Mitofusin 1 and mitofusin 2 are ubiquitinated in a PINK1/parkin-dependent manner upon induction of mitophagy. Hum Mol Genet. 2010;19(24):4861-70.

9. Geisler S, Holmstrom KM, Skujat D, Fiesel FC, Rothfuss OC, Kahle PJ, et al. PINK1/Parkin-mediated mitophagy is dependent on VDAC1 and p62/SQSTM1. Nat Cell Biol. 2010;12(2):119-31.

10. Poole AC, Thomas RE, Yu S, Vincow ES, Pallanck L. The mitochondrial fusion-promoting factor mitofusin is a substrate of the PINK1/parkin pathway. PLoS One. 2010;5(4):e10054.

11. Sarraf SA, Raman M, Guarani-Pereira V, Sowa ME, Huttlin EL, Gygi SP, et al. Landscape of the PARKIN-dependent ubiquitylome in response to mitochondrial depolarization. Nature. 2013;496(7445):372-6.

12. Narendra D, Tanaka A, Suen DF, Youle RJ. Parkin is recruited selectively to impaired mitochondria and promotes their autophagy. J Cell Biol. 2008;183(5):795803.

13. Dehay B, Martinez-Vicente M, Caldwell GA, Caldwell KA, Yue Z, Cookson MR, et al. Lysosomal impairment in Parkinson's disease. Mov Disord. 2013;28(6):72532.

14. Roosen DA, Cookson MR. LRRK2 at the interface of autophagosomes, endosomes and lysosomes. Mol Neurodegener. 2016;11(1):73.

15. Huang Y, Deng L, Zhong Y, Yi M. The Association between E326K of GBA and the Risk of Parkinson's Disease. Parkinsons Dis. 2018;2018:1048084.

16. O'Regan G, deSouza RM, Balestrino R, Schapira AH. Glucocerebrosidase Mutations in Parkinson Disease. J Parkinsons Dis. 2017;7(3):411-22. 
17. Gegg ME, Schapira AH. Mitochondrial dysfunction associated with glucocerebrosidase deficiency. Neurobiol Dis. 2016;90:43-50.

18. Gusdon AM, Zhu J, Van Houten B, Chu CT. ATP13A2 regulates mitochondrial bioenergetics through macroautophagy. Neurobiol Dis. 2012;45(3):962-72.

19. Gan-Or Z, Dion PA, Rouleau GA. Genetic perspective on the role of the autophagy-lysosome pathway in Parkinson disease. Autophagy. 2015;11(9):1443-57.

20. Ivanova MM, Changsila E, Iaonou C, Goker-Alpan O. Impaired autophagic and mitochondrial functions are partially restored by ERT in Gaucher and Fabry diseases. PLoS One. 2019;14(1):e0210617.

21. Pan T, Rawal P, Wu Y, Xie W, Jankovic J, Le W. Rapamycin protects against rotenone-induced apoptosis through autophagy induction. Neuroscience. 2009;164(2):541-51.

22. Fernandez-Mosquera L, Diogo CV, Yambire KF, Santos GL, Luna Sanchez M, Benit $\mathrm{P}$, et al. Acute and chronic mitochondrial respiratory chain deficiency differentially regulate lysosomal biogenesis. Sci Rep. 2017;7:45076.

23. Ivankovic D, Chau KY, Schapira AH, Gegg ME. Mitochondrial and lysosomal biogenesis are activated following PINK1/parkin-mediated mitophagy. J Neurochem. 2016;136(2):388-402.

24. Raimundo N, Fernandez-Mosquera L, Yambire KF, Diogo CV. Mechanisms of communication between mitochondria and lysosomes. Int J Biochem Cell Biol. 2016;79:345-9.

25. Honscher C, Mari M, Auffarth K, Bohnert M, Griffith J, Geerts W, et al. Cellular metabolism regulates contact sites between vacuoles and mitochondria. Dev Cell. 2014;30(1):86-94.

26. Audano M, Schneider A, Mitro N. Mitochondria, lysosomes, and dysfunction: their meaning in neurodegeneration. J Neurochem. 2018;147(3):291-309.

27. Demers-Lamarche J, Guillebaud G, Tlili M, Todkar K, Belanger N, Grondin M, et al. Loss of Mitochondrial Function Impairs Lysosomes. J Biol Chem. 2016;291(19):10263-76.

28. Graef M, Nunnari J. Mitochondria regulate autophagy by conserved signalling pathways. EMBO J. 2011;30(11):2101-14.

29. Bogetofte H, Jensen P, Ryding M, Schmidt SI, Okarmus J, Ritter L, et al. PARK2 Mutation Causes Metabolic Disturbances and Impaired Survival of Human iPSC-Derived Neurons. Front Cell Neurosci. 2019;13:297

30. Shaltouki A, Sivapatham R, Pei Y, Gerencser AA, Momcilovic O, Rao MS, et al. Mitochondrial alterations by PARKIN in dopaminergic neurons using PARK2 patient-specific and PARK2 knockout isogenic iPSC lines. Stem Cell Reports. 2015;4(5):847-59.

31. Hurbain I, Romao M, Bergam P, Heiligenstein X, Raposo G. Analyzing Lysosome-Related Organelles by Electron Microscopy. Methods Mol Biol. 2017;1594:43-71. 
32. Kane MS, Paris A, Codron P, Cassereau J, Procaccio V, Lenaers G, et al. Current mechanistic insights into the CCCP-induced cell survival response. Biochem Pharmacol. 2018;148:100-10.

33. Dawson TM. Parkin and defective ubiquitination in Parkinson's disease. J Neural Transm Suppl. 2006(70):209-13.

34. Park J, Lee SB, Lee S, Kim Y, Song S, Kim S, et al. Mitochondrial dysfunction in Drosophila PINK1 mutants is complemented by parkin. Nature. 2006;441(7097):1157-61.

35. Fivenson EM, Lautrup S, Sun N, Scheibye-Knudsen M, Stevnsner T, Nilsen H, et al. Mitophagy in neurodegeneration and aging. Neurochem Int. 2017;109:202-9.

36. Fraldi A, Klein AD, Medina DL, Settembre C. Brain Disorders Due to Lysosomal Dysfunction. Annu Rev Neurosci. 2016;39:277-95.

37. Song P, Trajkovic K, Tsunemi T, Krainc D. Parkin Modulates Endosomal Organization and Function of the Endo-Lysosomal Pathway. J Neurosci. 2016;36(8):2425-37.

38. Plotegher N, Duchen MR. Crosstalk between Lysosomes and Mitochondria in Parkinson's Disease. Front Cell Dev Biol. 2017;5:110.

39. Baixauli F, Acin-Perez R, Villarroya-Beltri C, Mazzeo C, Nunez-Andrade N, Gabande-Rodriguez E, et al. Mitochondrial Respiration Controls Lysosomal Function during Inflammatory T Cell Responses. Cell Metab. 2015;22(3):485-98.

40. Miyamoto Y, Kitamura N, Nakamura Y, Futamura M, Miyamoto T, Yoshida $\mathrm{M}$, et al. Possible existence of lysosome-like organella within mitochondria and its role in mitochondrial quality control. PLoS One. 2011;6(1):e16054.

41. Tai H, Wang Z, Gong H, Han X, Zhou J, Wang X, et al. Autophagy impairment with lysosomal and mitochondrial dysfunction is an important characteristic of oxidative stress-induced senescence. Autophagy. 2017;13(1):99-113.

42. de la Mata M, Cotan D, Villanueva-Paz M, de Lavera I, Alvarez-Cordoba M, Luzon-Hidalgo R, et al. Mitochondrial Dysfunction in Lysosomal Storage Disorders. Diseases. 2016;4(4).

43. Todkar K, Ilamathi HS, Germain M. Mitochondria and Lysosomes: Discovering Bonds. Front Cell Dev Biol. 2017;5:106.

44. Zhang X, Cheng X, Yu L, Yang J, Calvo R, Patnaik S, et al. MCOLN1 is a ROS sensor in lysosomes that regulates autophagy. Nat Commun. 2016;7:12109.

45. Tan S, Yu CY, Sim ZW, Low ZS, Lee B, See F, et al. Pomegranate activates TFEB to promote autophagy-lysosomal fitness and mitophagy. Sci Rep. 2019;9(1):727.

46. Palmieri M, Impey S, Kang H, di Ronza A, Pelz C, Sardiello M, et al. Characterization of the CLEAR network reveals an integrated control of cellular clearance pathways. Hum Mol Genet. 2011;20(19):3852-66.

47. Fernandes HJ, Hartfield EM, Christian HC, Emmanoulidou E, Zheng Y, Booth $\mathrm{H}$, et al. ER Stress and Autophagic Perturbations Lead to Elevated Extracellular alpha- 
Synuclein in GBA-N370S Parkinson's iPSC-Derived Dopamine Neurons. Stem Cell Reports. 2016;6(3):342-56.

48. Abou-Sleiman PM, Muqit MM, Wood NW. Expanding insights of mitochondrial dysfunction in Parkinson's disease. Nat Rev Neurosci. 2006;7(3):20719.

49. Ridler C. Parkinson disease: Lysosome storage disorder risk genes linked to PD. Nat Rev Neurol. 2018;14(1):3.

50. Alroy J, Garganta C, Wiederschain G. Secondary biochemical and morphological consequences in lysosomal storage diseases. Biochemistry (Mosc). 2014;79(7):619-36.

51. O'Brien JS, Bernett J, Veath ML, Paa D. Lysosomal storage disorders. Diagnosis by ultrastructural examination of skin biopsy specimens. Arch Neurol. 1975;32(9):592-9.

52. Vogler C, Rosenberg HS, Williams JC, Butler I. Electron microscopy in the diagnosis of lysosomal storage diseases. Am J Med Genet Suppl. 1987;3:243-55.

53. Guerra F, Girolimetti G, Beli R, Mitruccio M, Pacelli C, Ferretta A, et al. Synergistic Effect of Mitochondrial and Lysosomal Dysfunction in Parkinson's Disease. Cells. 2019;8(5).

54. Sánchez-Danés A, Richaud-Patin Y, Carballo-Carbajal I, Jiménez-Delgado S, Caig C, Mora S, et al. Disease-specific phenotypes in dopamine neurons from human iPS-based models of genetic and sporadic Parkinson's disease. EMBO Mol Med. 2012;4(5):380.95.

55. Bendikov-Bar I, Rapaport D, Larisch S, Horowitz M. Parkin-mediated ubiquitination of mutant glucocerebrosidase leads to competition with its substrates PARIS and ARTS. Orphanet J Rare Dis. 2014;9:86. 


\section{Figure legends}

Figure 1: General characterization of neurons derived from $P A R K 2 \mathrm{KO}$ and healthy isogenic induced pluripotent stem cells (iPSCs).

A) Graphical overview of the differentiation of iPSCs to neural stem cells (NSCs) and fully committed dopaminergic neurons. B) Immunofluorescence analysis of MAP2 (mature neurons, red), and TH (dopaminergic neurons, green) expression in PARK2 KO iPSC and control iPSC lines at day 25 of differentiation. Cell nuclei are visualized using DAPI (blue). Representative pictures are shown. Scale bar: $50 \mu \mathrm{m}$. C-D) Quantitative assessment of C) MAP2 + mature neurons and D) $\mathrm{TH}+$ dopaminergic neurons in PARK2 $\mathrm{KO}$ and control iPSC lines. All data are presented as mean $\pm \mathrm{SEM}, \mathrm{n}=15 ; 5$ independent differentiations. E-F) Western blotting and densitometry analysis of E) MAP2 and F) TH protein expression levels in PARK2 KO and control iPSC lines. Protein expression levels were normalized to $\alpha$-actin. Data are presented as mean \pm SEM; 3 independent experiments. G) qPCR analysis for midbrain/dopaminergic markers (EN1, NURR1 and GIRK2). GAPDH, 18S, HPRT were used as endogenous references. Data were normalized to control levels and presented as mean \pm SEM, 2 independent experiments.

\section{Figure 2: PARK2 KO neurons exhibit aberrant lysosomes.}

A, B) Western blotting analysis of the abundance of lysosomal markers B) LAMP1 and C) LAMP2a. Expression levels were normalized to $\beta$-actin and are shown relative to control neurons. Data are presented as mean \pm SEM of at least 3 independent differentiations. $* \mathrm{p}<0.05$, and $* * \mathrm{p}<0.01$, analyzed using Student's t-test. C) Representative TEM micrographs showing the ultrastructure of lysosomes in healthy control (upper image) and PARK2 KO (bottom image) neurons. Scale bar: $100 \mathrm{~nm}$. D) Quantification of the lysosomal number per TEM micrograph showing lysosomal accumulation in PARK2 $\mathrm{KO}$ neurons. E) Lysosomal size, as a measurement of average lysosomal area, was increased in PARK2 KO neurons. F) Mean Grey Value of individual lysosomes was reduced in PARK2 KO neurons. G) Percentage of electronlucent lysosomes among all lysosomes in a given neuronal population. Data are presented as mean \pm SEM, $n=6$ TEM grids, 3 independent differentiations (in total 45 TEM micrograps per cell line were analyzed. ${ }^{*} \mathrm{p}<0.05$, and $* * \mathrm{p}<0.01$, analyzed using Student's t-test. 


\section{Figure 3: Increased lysosomal area caused by parkin deficiency and CCCP treatment.}

A-E) Temporal changes in LAMP1 (green) immunoreactivity in iPSC-derived neurons from a healthy control and PARK2 KO cells. Cell nuclei were visualized using DAPI (blue). Scale bar: $20 \mu \mathrm{m}$. F) Quantification of the area of LAMP1+ lysosomes normalized to the number of DAPI+ nuclei showing no difference between PARK2 KO and control cells at days 0 and 10, while a significant increase was observed at day 25 and later time points. Data are presented as mean \pm SEM of 3 independent differentiations. ${ }^{* *} \mathrm{p}<0.01, * * * \mathrm{p}<0.001$, ns: not significant, analyzed with Student's t-test. G) LAMP1 (green) and DAPI (blue) immunofluorescence staining of PARK2 KO neurons and isogenic controls at day 25 after CCCP treatment (10 $\mu \mathrm{M}, 48 \mathrm{~h})$. Scale bar: $20 \mu \mathrm{m}$. H) Significant increase of lysosomal area in both control and the PARK2 KO neurons after CCCP exposure. Data presented as mean $\pm \mathrm{SEM}$, three independent differentiations. ${ }^{*} \mathrm{p}<0.05,{ }^{*} \mathrm{p}<0.01$, ns: not significant, analyzed using one-way ANOVA.

\section{Figure 4: Perturbed lysosomal function and altered autophagic flux in PARK2 KO} neurons.

A) General intracellular lysosomal enzyme activity manifested by generation of the fluorescence signal in PARK2 $\mathrm{KO}$ and control neurons. Scale bar: $50 \mu \mathrm{m}$. B) Quantification of the signal intensity showed a significant decrease in the overall functional activity of lysosomal enzymes in the PARK2 $\mathrm{KO}$ neurons compared to controls. C) Kinetics of enzymatic activity of $\beta$-galactosidase ( $\beta$-Gal) based on relative fluorescence intensity versus time. Graph represents changes in the PARK2 KO neurons (blue dashed line) and control neurons (grey solid line), positive control (red dashed line), and blank (green dot-dash line). D) The specific $\beta$-Gal activity was significantly reduced for the PARK2 KO neurons. E) Glucocerebrosidase (GCase) enzyme activity was significantly increased for PARK2 KO neurons compared to controls. F) Western blotting showed no changes in GCase levels. Expression levels were normalized to $\beta$ actin and shown relative to control neurons. G) GCase enzyme activity normalized to GCase levels was significantly increased in the PARK2 KO neurons. (H-K) Alteration of autophagy in PARK2 KO neurons. H) Differentiated cells were incubated with 10 
$\mathrm{nM}$ bafilomycin A1 (BAF) for 6h or with equivalent amount of DMSO as vehicle (UNTR) and western blotting was performed for LC3. I) Total LC3 (LC3-I + LC3-II) levels and J) LC3-II/LC3-I ratios for each group was calculated by densitometric analysis and normalized to the level of $\alpha$-actin. K) The autophagic flux manifested as the ratio of LC3 between BAF and UNTR of the same group. All data presented as mean \pm SEM, 2-3 independent differentiations. ${ }^{*} \mathrm{p}<0.05,{ }^{*} \mathrm{p}<0.01,{ }^{*} * \mathrm{p}<0.001, \mathrm{~ns}$ : not significant, analyzed using Student's t-test.

\section{Table legends}

Table 1: Changes in lysosomal content in $P A R K 2$ KO neurons revealed by proteomic analysis.

Table listing lysosomal proteins identified by proteomic analysis with the ratio of their protein levels in PARK2 KO neurons compared to controls; q-value (FDR-adjusted pvalue) and number of unique peptides, $n=3$, three independent differentiations. 
bioRxiv preprint doi: https://doi org/101101/734244; this version posted August 13, 2019. The copyright holder for this preprint (which was

\section{Figure 1}
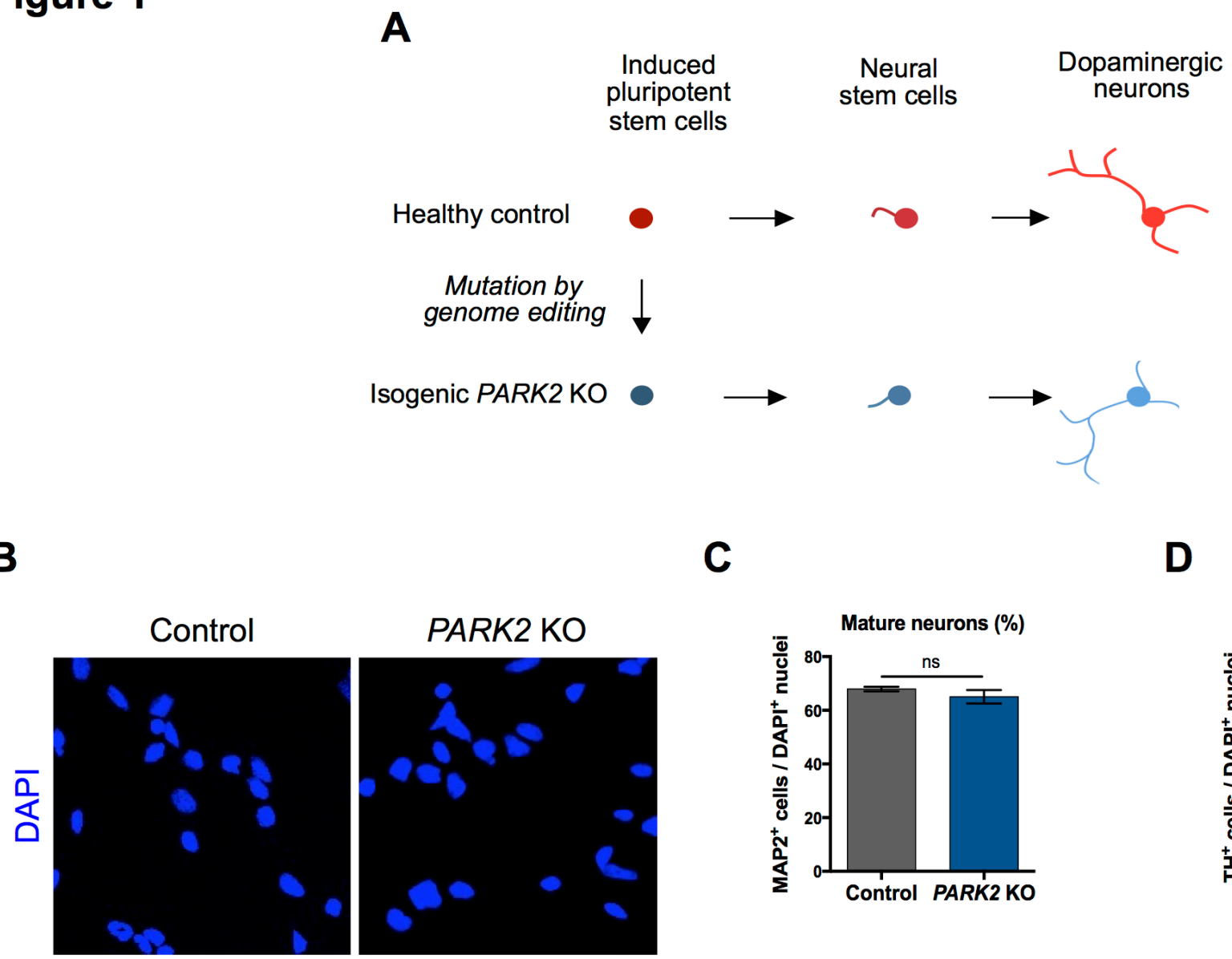

Dopaminergic neurons (\%)
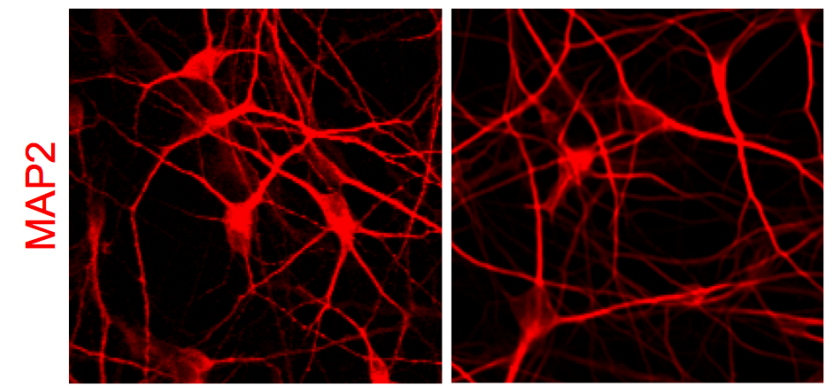

$\mathbf{E}$
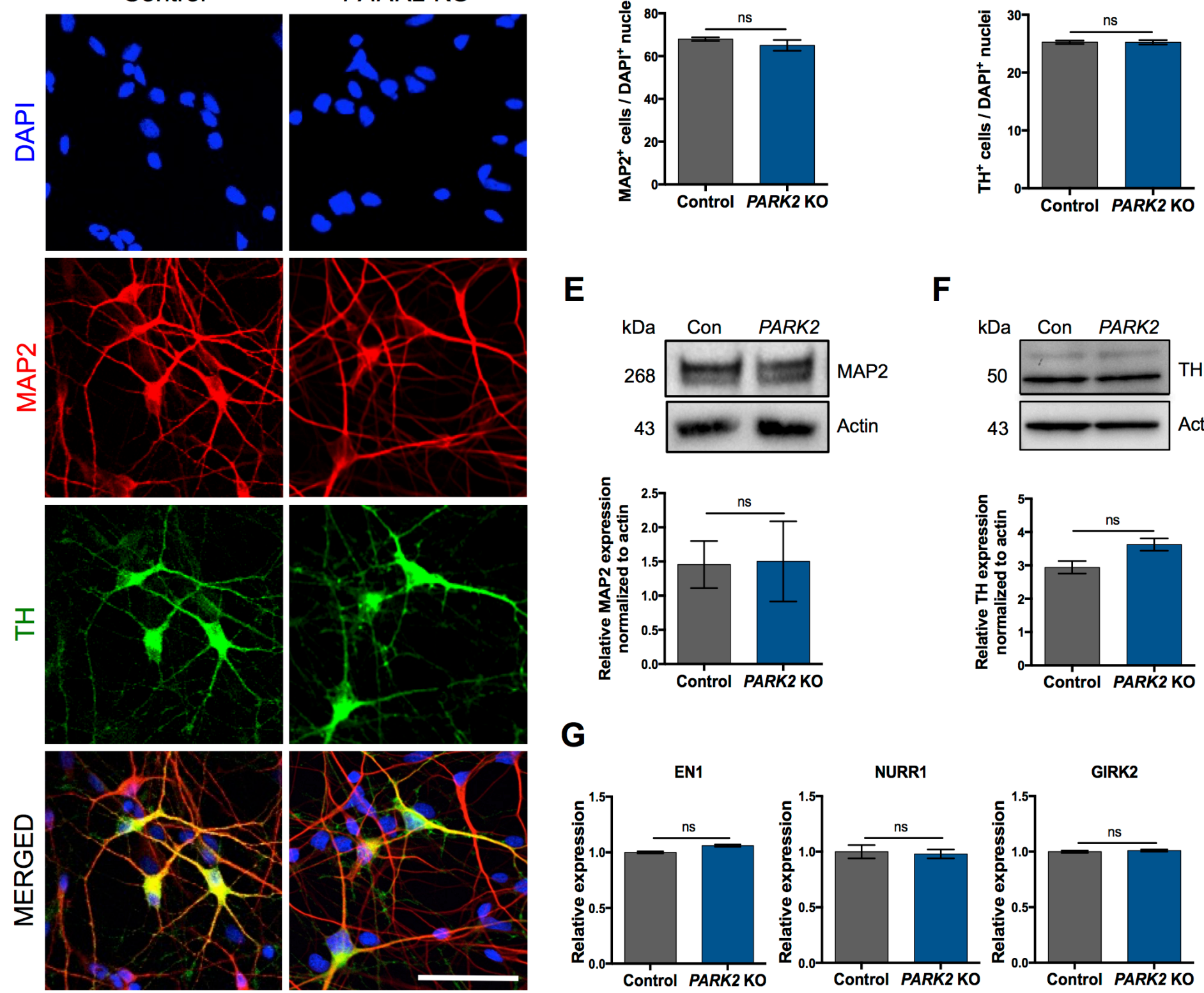

G
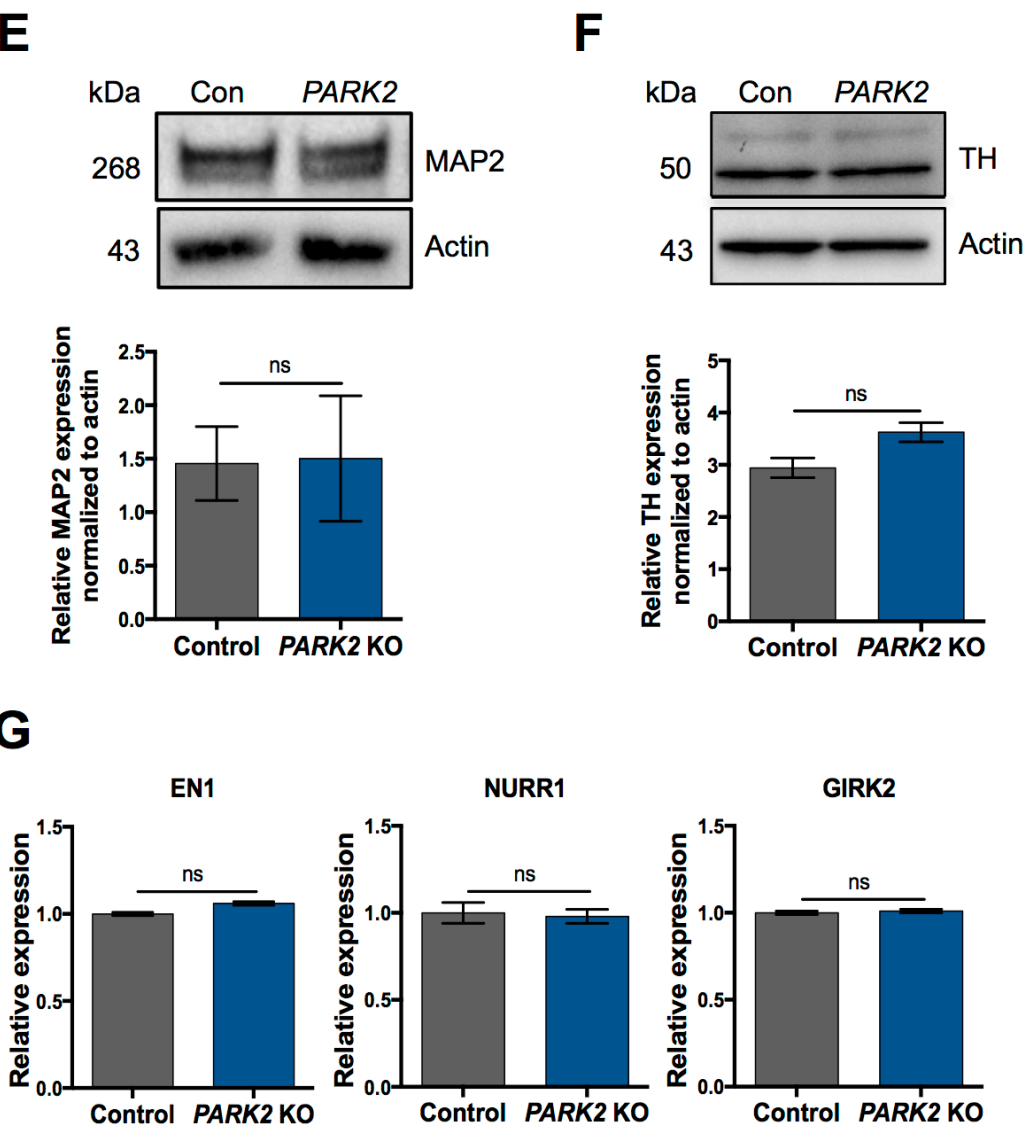
bioRxiv preprint doi: https://doi org/10 1101/734244; this version posted August 13,2019. The copyright holder for this preprint (which was not certified by peer review) is the author/funder, who has granted bioRxiv a license to display the preprint in perpetuity. It is made available under aCC-BY-NC-ND 4.0 International license.

\section{Figure 2}

A

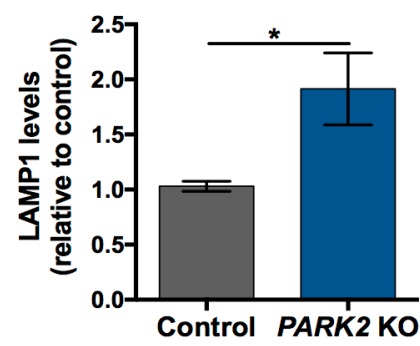

C
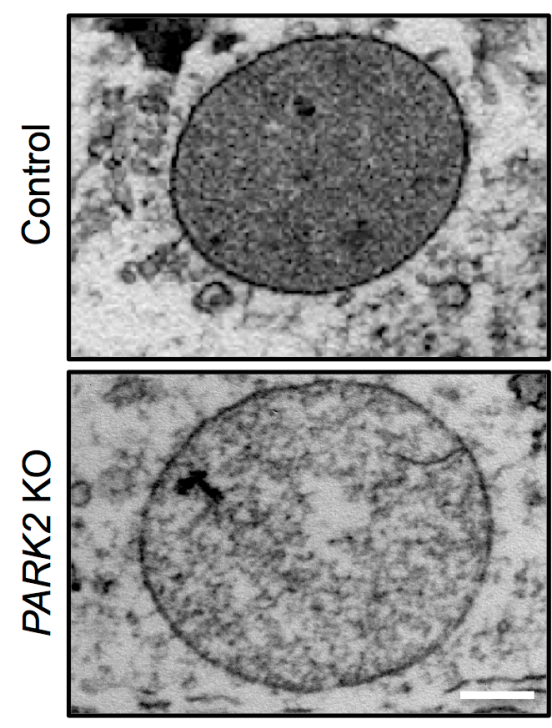

B
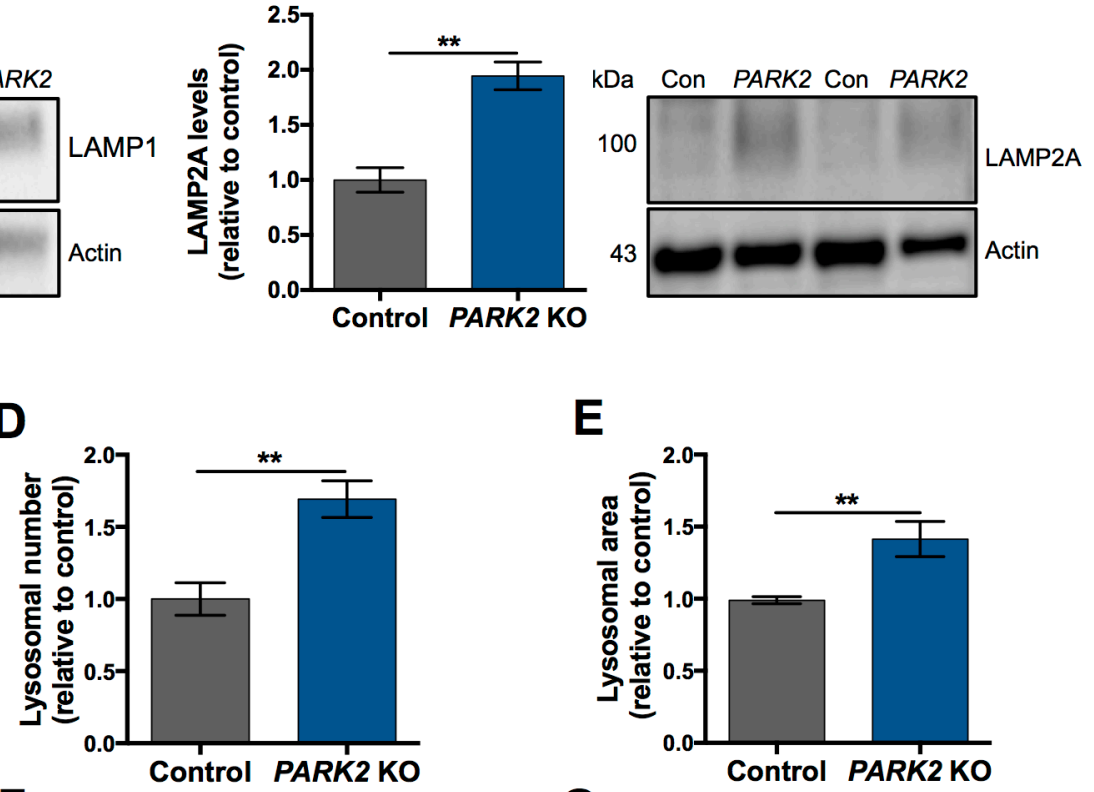

F

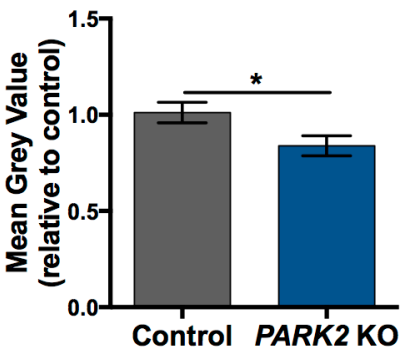

E

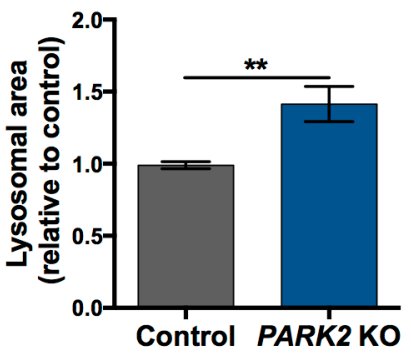

G

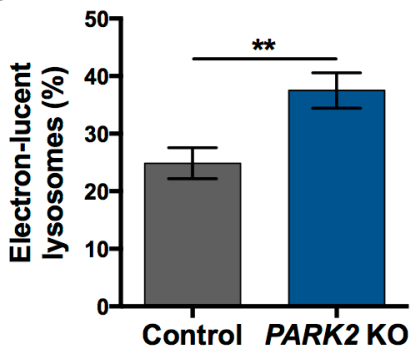


Figure 3

DAPI/LAMP1

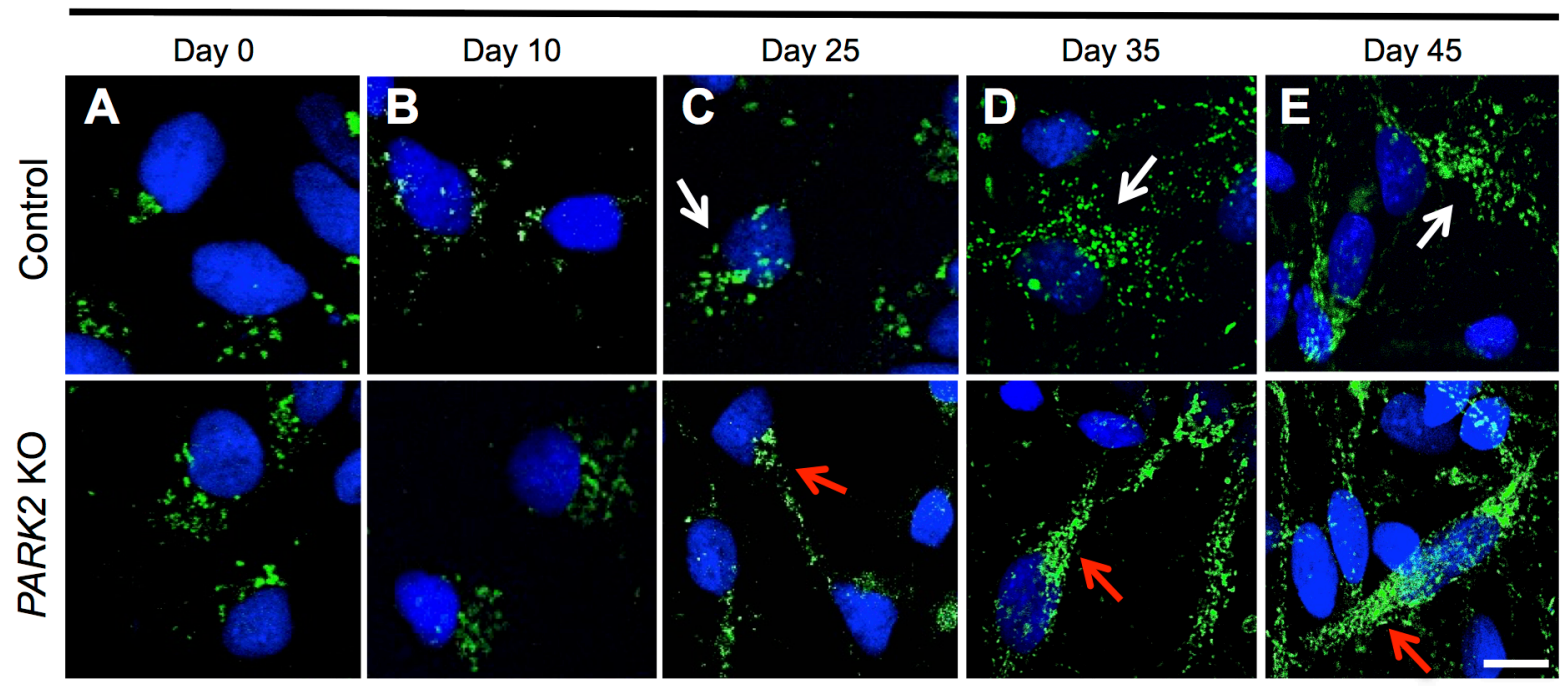

$\mathbf{F}$

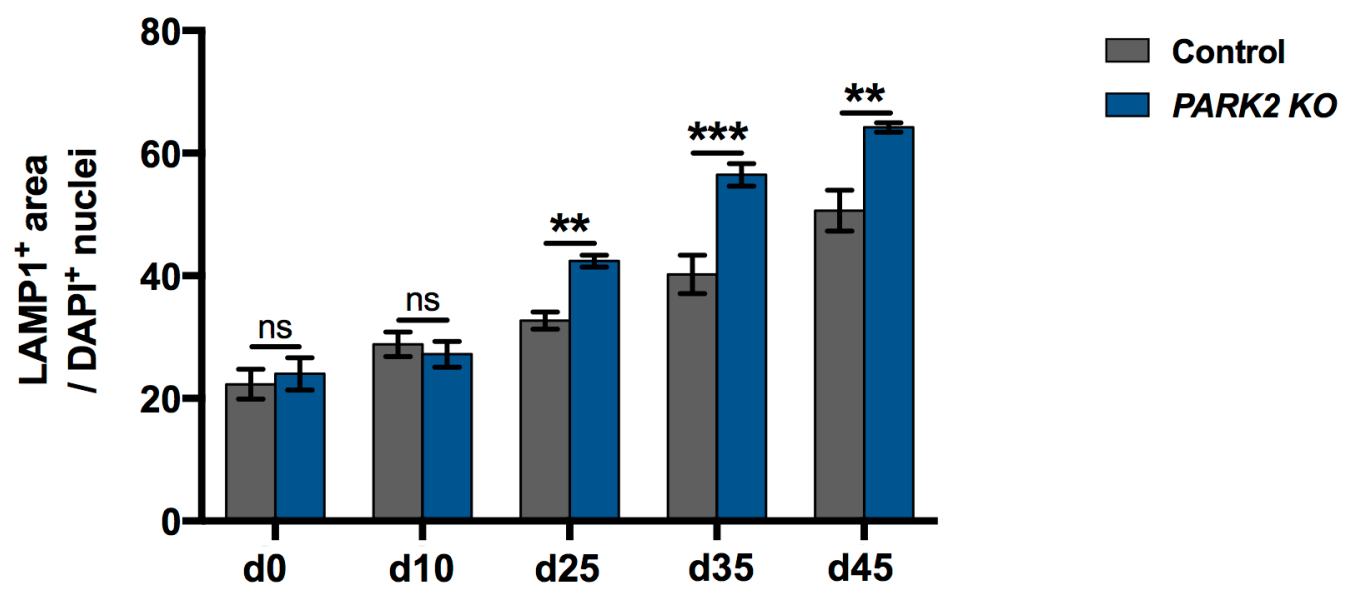

G

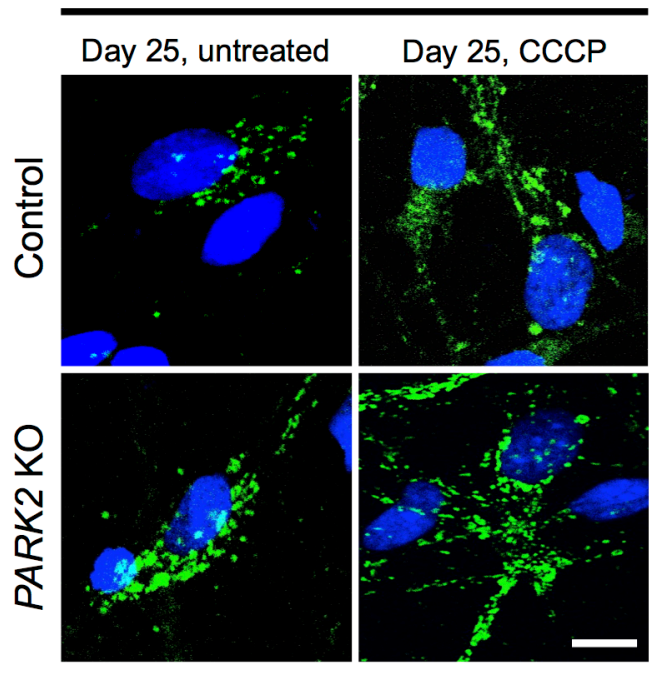

H

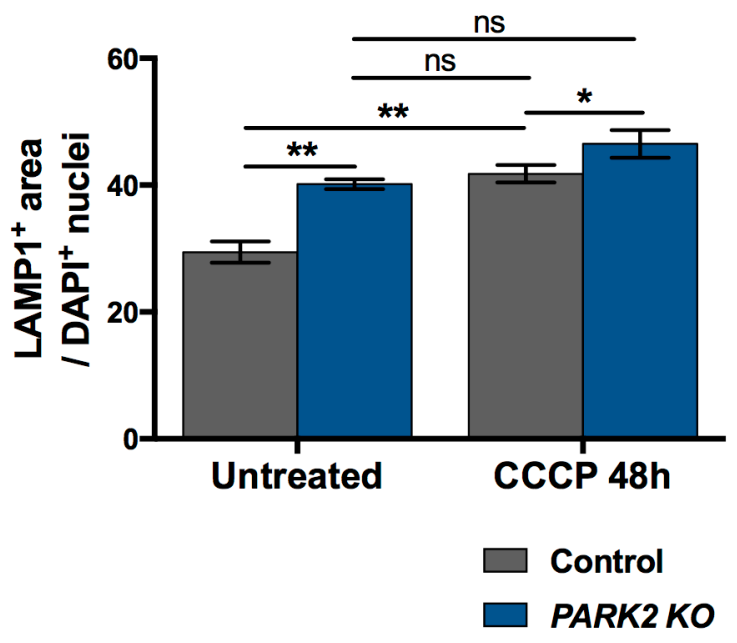


bioRxiv preprint doi: https://doi org/101101/734244; this version posted August 13, 2019. The copyright holder for this preprint (which was

\section{Figure 4}

A

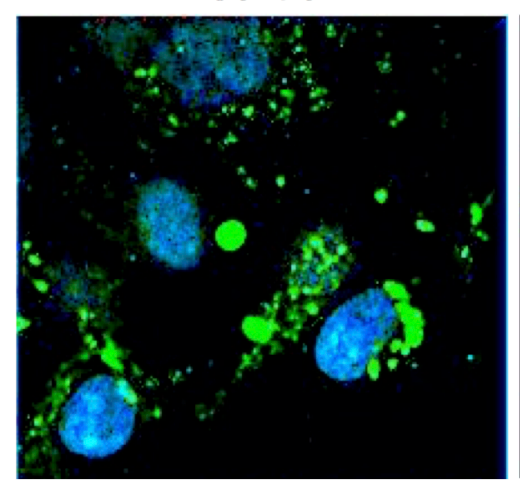

C
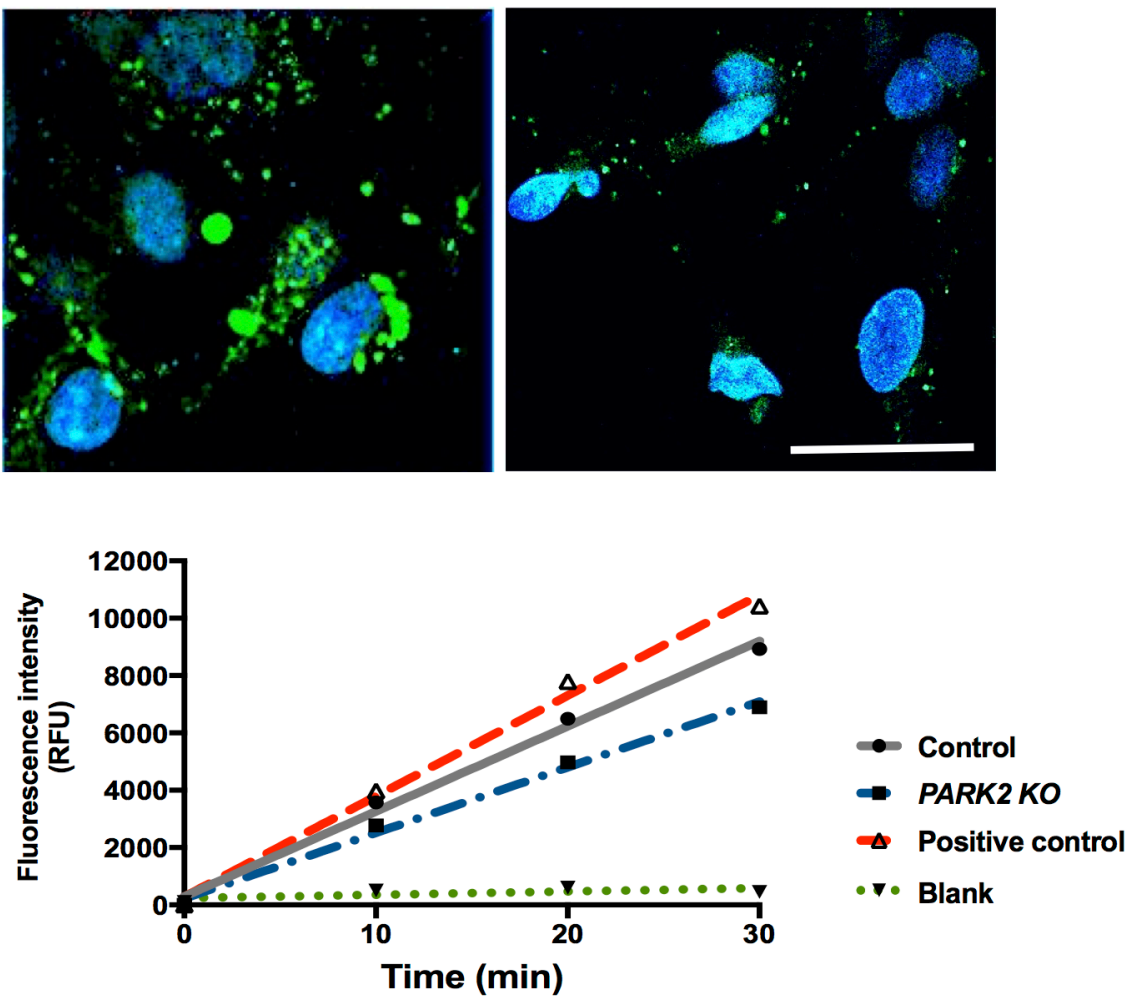

B

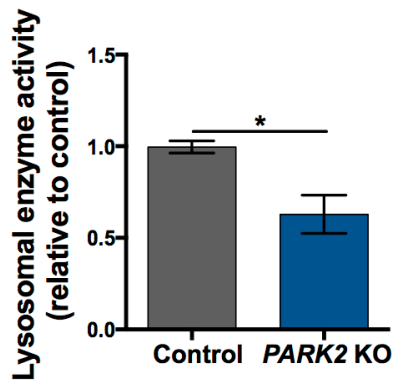

D

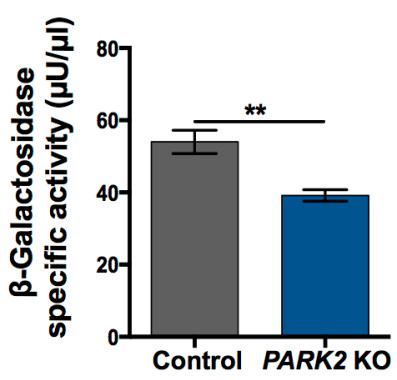

E

F
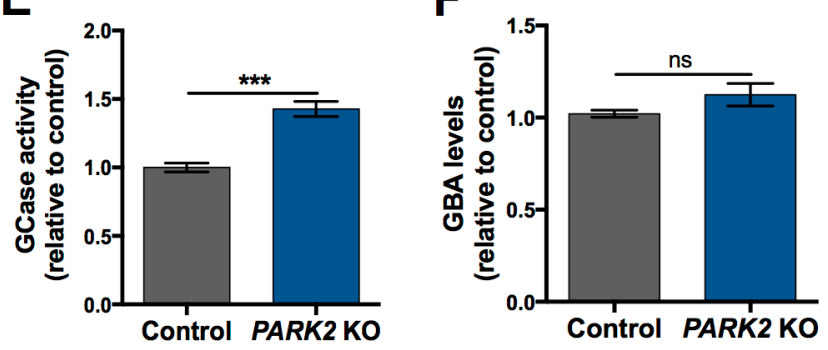

KDA Con PARK2 Con PARK2

60

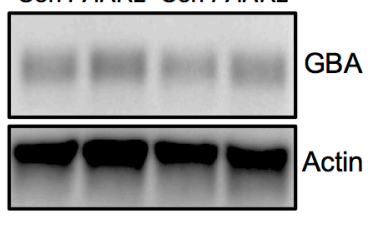

G

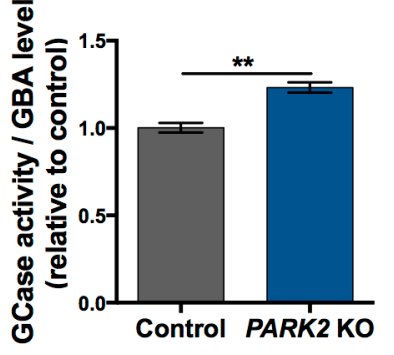

H
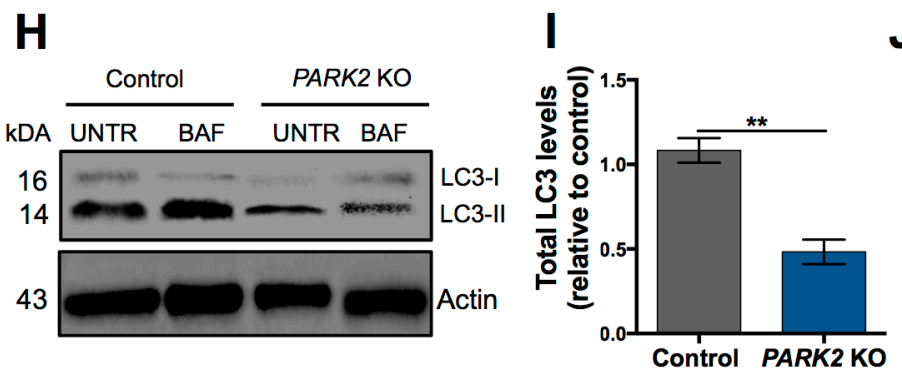

K

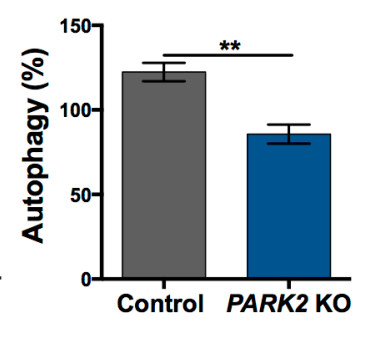




\section{Table 1}

\begin{tabular}{|c|c|c|c|c|c|}
\hline Accession & Gene name & Description & $\begin{array}{c}\text { PARK2 KO I } \\
\text { Control }\end{array}$ & q-value & $\begin{array}{c}\text { Unique } \\
\text { Peptides }\end{array}$ \\
\hline P27449 & ATP6V0C & V-type proton ATPase $16 \mathrm{kDa}$ proteolipid subunit & 1.56 & 0.005 & 4 \\
\hline Q6IQ22 & RAB12 & Ras-related protein Rab-12 & 1.31 & 0.014 & 9 \\
\hline Q9Y5W7 & SNX14 & Sorting nexin-14 & 1.30 & 0.018 & 2 \\
\hline Q8IY95 & TMEM192 & Transmembrane protein 192 & 1.25 & 0.025 & 2 \\
\hline O15400 & STX7 & Syntaxin-7 & 1.23 & 0.036 & 13 \\
\hline Q96GC9 & VMP1 & Vacuole membrane protein 1 & 1.21 & 0.035 & 3 \\
\hline Q9H267 & VPS33B & Vacuolar protein sorting-associated protein 33B & 0.87 & 0.039 & 7 \\
\hline P78537 & BLOC1S1 & Biogenesis of lysosome-related organelles complex 1 subunit 1 & 0.85 & 0.042 & 3 \\
\hline Q969J3 & BORCS5 & BLOC-1 related complex subunit 5 & 0.85 & 0.037 & 2 \\
\hline Q9H305 & CDIP1 & Cell death-inducing p53-target protein 1 & 0.84 & 0.028 & 2 \\
\hline P07858 & CTSB & Cathepsin B & 0.84 & 0.047 & 2 \\
\hline Q9UN37 & VPS4A & Vacuolar protein sorting-associated protein $4 \mathrm{~A}$ & 0.83 & 0.036 & 8 \\
\hline P86790 & CCZ1B & Vacuolar fusion protein CCZ1 homolog B & 0.82 & 0.020 & 3 \\
\hline Q8TAF3 & WDR48 & WD repeat-containing protein 48 & 0.81 & 0.042 & 8 \\
\hline 014964 & HGS & Hepatocyte growth factor-regulated tyrosine kinase substrate & 0.79 & 0.015 & 5 \\
\hline P61073 & CXCR4 & C-X-C chemokine receptor type 4 & 0.79 & 0.016 & 3 \\
\hline O43237 & DYNC1LI2 & Cytoplasmic dynein 1 light intermediate chain 2 & 0.74 & 0.017 & 19 \\
\hline Q01484 & ANK2 & Ankyrin-2 & 0.72 & 0.009 & 167 \\
\hline P61916 & NPC2 & NPC intracellular cholesterol transporter 2 & 0.69 & 0.020 & 3 \\
\hline $\mathrm{P} 60520$ & GABARAPL2 & Gamma-aminobutyric acid receptor-associated protein-like 2 & 0.67 & 0.004 & 6 \\
\hline P98164 & LRP2 & Low-density lipoprotein receptor-related protein 2 & 0.63 & 0.003 & 16 \\
\hline $\mathrm{Q} 9 \mathrm{H} 492$ & MAP1LC3A & Microtubule-associated proteins $1 \mathrm{~A} / 1 \mathrm{~B}$ light chain $3 \mathrm{~A}$ & 0.57 & 0.003 & 2 \\
\hline
\end{tabular}

